\title{
.. CYTOCHONDRIAL ASPECTS OF CELLULAR PATHOLOGY
}

\author{
BY \\ JOHN W. HARMAN \\ From the Department of Pathology, University College, Dublin
}

\section{Cytochondrial Composition of Cytoplasm}

Although the introduction by Purkinje (1825) of the term protoplasm may have established a conceptual advance, it also provided for over-simplification and led to the separation of cytoplasm into hyaloplasm and granuloplasm, with emphasis on the former. This dichotomy is still apparent in the emphatic works of numerous biologists (Seifriz, 1942 ; Frey-Wyssling, 1948), who relegate the granular constituents of cytoplasm to incidental roles. Accumulated evidence has reversed this trend and redistributed the cytoplasmic structure into multiple particulates. The Pasteur and Crabtree effects with particulate and soluble systems from the cytoplasm have indicated that the phenomena are mediated by interaction between these components (Aisenberg and Potter, 1957). Current perspective accords to cell particulates an essential participation in living processes, so that it is imperative to evaluate their significance and importance in cellular pathology.

By utilizing such diverse techniques as phasecontrast microscopy (Zollinger, 1950), electron microscopy (Dalton, 1953), and the homogenization of cells with controlled differential centrifugation (de Duve and Berthet, 1954), a basic concept of particulate cytoplasmic structure has been evolved. The range of particles extends from the easily visible mitochondria and the heterogeneous microsomes to the units appreciated only by electron microscopy. Schemes of subdivision have been advanced which differ only in detail concerning certain borderline particles (Novikoff, 1956a ; Kuff, Hogeboom, and Dalton, 1956). We refer to all cytoplasmic organelles collectively as cytochondria (Opie, 1948 ; Kitiyakara and Harman, 1953).

One scheme of cell structure devised by Novikoff (1956a) is shown in the illustrations of the rat parenchymatous liver cell (Figs. 1-4). It has been used by cytochemists (Claude, 1946) and pathologists (Christie and Judah, 1953) for analysis of cytoplasmic reactions. It comprises a manageable system for the elucidation of pathological events at subcellular level. A recent study of uterine mucosa shows a similar picture (Nilsson, 1958). The mitochondria, which had been observed and isolated from cytoplasm in the early nineteenth century (Kölliker, 1857), were established as cytoplasmic constituents by Altmann (1894) in a study of cytoplasmic structure, using freeze-dry technique, and were isolated in bulk for chemical analysis by Bensley and Hoerr (1934) and by Hogeboom, Claude, and Hotchkiss (1946). It was observed that the integrated enzymes, which catalyse Krebs's tricarboxylic acid cycle and oxidative phosphorylation (Green, Loomis, and Auerbach, 1948), were located almost exclusively in the mitochondria (Harman, 1950a). It was proposed that mitochondrial integrity and function of the integrate cycle were mutually dependent (Harman, 1950b; Judah and Williams-Ashman, 1951). Although the contention that the entire Krebs's cycle resided in the mitochondria was challenged (Schneider and Hogeboom, 1951) a great deal of evidence identified the component enzymes within mitochondria. With the recent observations of Ernster and Navazio (1957) it can be accepted that the cycle can operate exclusively within these units. The importance of this fact to cell metabolism and pathology is stressed by the quantitative predominance of the particles, which comprise $30 \%$ of cell mass and number 2,500 per cell tightly packed (Allard, Mathieu, De Lamirande, and Cantero, 1952), as illustrated in Fig. 5, which is a photomicrograph of a rat liver cell prepared by Kaltenbach's method (1954). The characteristic fine structure of the mitochondria has been catalogued for many tissues by Palade (1952), and this structure, with inner lamina and outer interface, is shown in Fig. 6. It has been disputed in several types of mitochondria (Weinreb and Harman, 1955 ; Powers, Ehret, and Roth, 1955), as shown in Fig. 7.

The significance of this ultrastructure has been strengthened by the correlation of various enzymes and systems with its constituents. The 


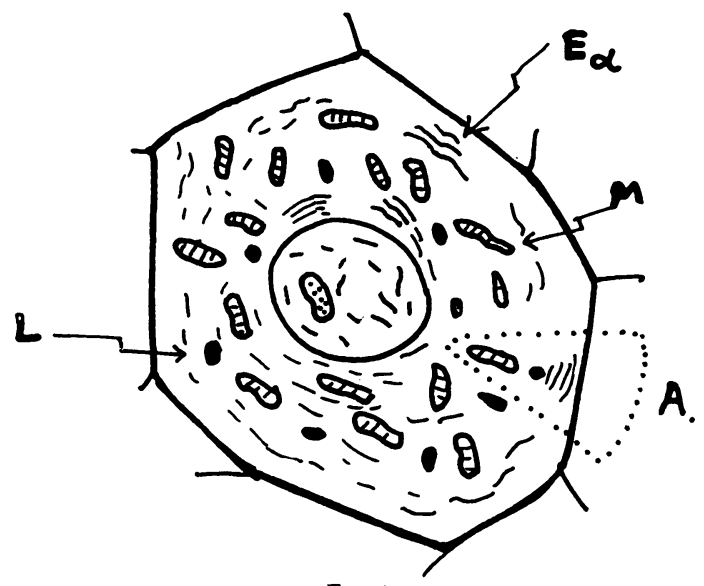

FIG. 1

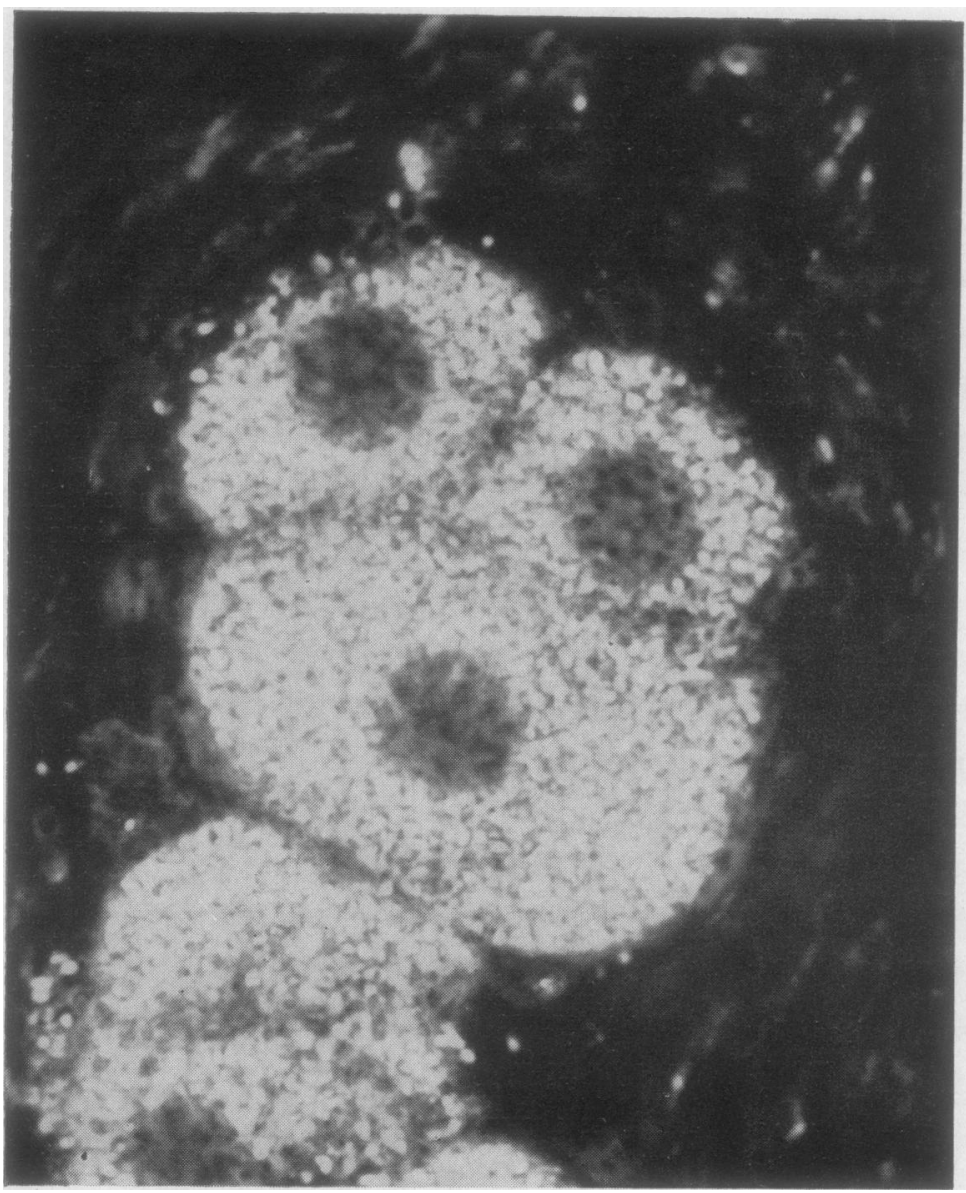

FIG. 5.-Several liver cells isolated in a metabolically active state are illustrated with light contrast phase microscopy. The cytoplasm is completely crammed with dense, rodlet mitochondria. Cells isolated by Kaltenbach's technique (1954) in buffered saline. $\times 1,500$.

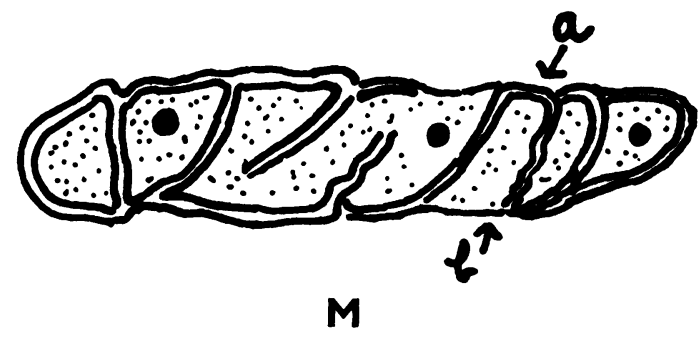

FIG. 2

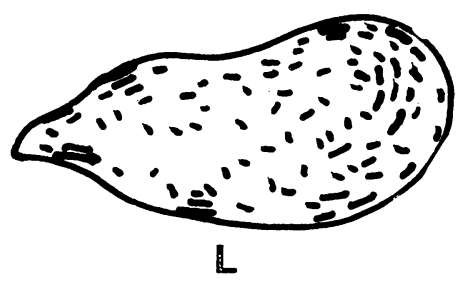

FIG. 3

FIG. 1.-Diagrammatic representation of parenchymal cell particulates includes $\overrightarrow{\vec{c}}$ (M) mitochondria, (L) lysosomes and o fat bodies, and (E) orgastoplasm of endoplasmic reticulum. Segment components are magnified in Figs. 2, and 4.

FIG. 2.-The mitochondrion is depicted, with looping, doubled membranes and lamellae. At "a "a peripheral loop is indicated, and at " $b$ " the double membrane is replaced by a single interface. This was drawn from representative liver mitochondria. The inner fine gel contains several highly electron-dense particles, which are especially large in uterine mucosal cells.

FIG. 3.-The lysosome is drawn after the representations of Novikoff et al. (1956). A characteristic interior particulate composition is evident from his electron micrographs, and the fibrous gel of the mitochondria is conspicuously absent.

FIG. 4.-Two interpretations of the endoplasmic reticulum are presented. In $S$ the observation of Sjöstrand, which regards the network as ribbon-like, is manifest, and the inner granules adherent to the lining of the interface. In $P$, which displays Palade's view, the orgastoplasm is regarded as a series of concatenated vesicles, each with its complement of granules. The granules are interpreted as ribonucleic acid particles.

FIG. 6.-Portion of a rodlet mitochondrion in a kidney cell manifests the inner laminae and surface loops, which appear to fuse as limiting surface membranes. This is an illustration from Rhodin (1954) by permission. Many electron opaque inner particles are visible. 

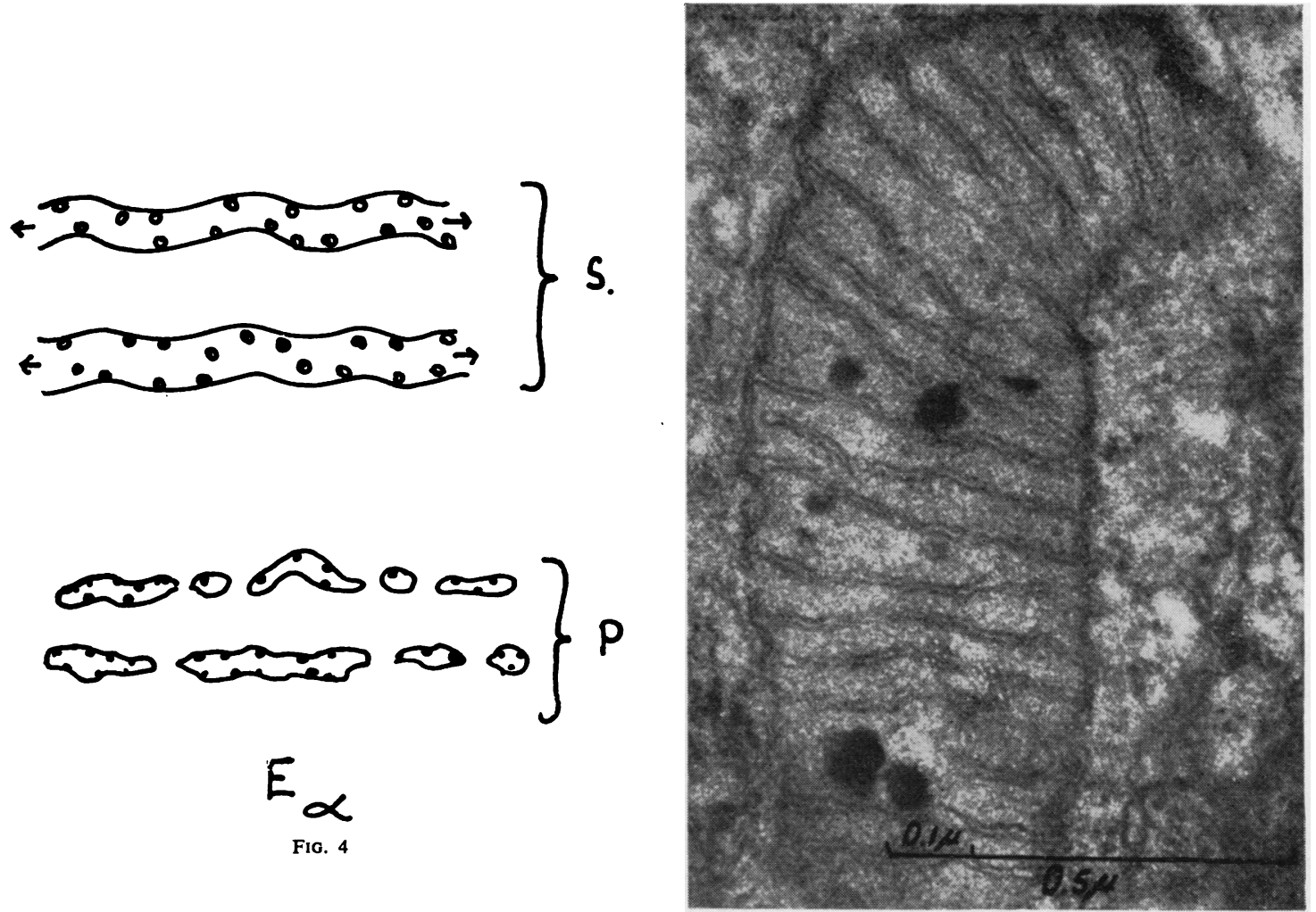

Fig. 6



FIG. 7.-A mitochondrion from skeletal muscle of pigeon breast is composed of transverse laminae, without limiting peripheral double membrane. Electron drift was excluded in the photomicrograph by clear demonstration of the perpendicular fibrillae in the myofibrils, indicating that lack of surface membrane is not artifactual. 
adenotriphosphatases of the mitochondrion are bound to the ribbed hull and defy elution, although a considerable portion of the nitrogen may be made soluble (Harman and Kitiyakara, 1955). On the other hand, the succinoxidase system and the electron chain occupy a sequential distribution in the laminae, and are obtained by mechanical, sonic, and digitonin disruption, which yields respiratory assemblies capable of phosphorylation (Ziegler, Linnane, and Green, 1958 ; Cran ミ, 1958 ; Kielley and Bronk, 1958; Cooper and Lehninger, 1956). Furthermore the susceptibility of the mitochondrial matrix and folded inner fibrous gel to swell and change their form depends on the redox state of electron carrier assemblies on the laminae (Hunter, Davis, and Carlat, 1956). When carriers are reduced there is limited reactivity to agents such as thyroxin (Lehninger and Ray, 1957). It is apparent therefore that the nutritive condition of the cell determines its reaction to injury.

There are particles of the same dimension and of similar pyknic gravitational density with mitochondria, one of which has been designated "lysosome" by de Duve, Pressman, Gianetto, Wattiaux, and Appelmans (1955) and further identified by electron microscopy (Novikoff, Beaufay, and de Duve, 1956). Its separation from mitochondria by differential gradients indicates that this unit is peculiar because of an exceptional content of hydrolytic, phosphoroclastic enzymes and glucuronidase. The injurious consequences on cell activity when their enzymes are released is apparent. The second particle, located in liver, is associated with iron metabolism and so has been called "siderosome" (Richter, 1957). Some very minute mitochondria, such as the "ultramitochondrioma" of Oberling, Bernhard, Febvre, and Harel (1951), have received special treatment and interpretation as regenerative precursors.

Microsomes (Claude, 1946) were for many years a heterogeneous group. They were distinguishable from heavier particles not only by difference in size and density but by a characteristically high content of ribonucleic acid. Monné (1948) discussed them as the chromidia of the intact cell. With better understanding from electron microscopy (Palade and Siekevitz, 1956) it is clear that they are derived from endoplasmic reticulum or ergastoplasm which is a series of minute vesicles containing tiny ribonucleoprotein particles (see, however, recent studies by Sjöstrand and Baker (1958) which contest the validity of Pakade's (1955a) $150 \AA$ particles of ribonucleic acid in the microsomes). The minute vesicles are arranged with some regularity in strings throughout the cytoplasm in three-dimensional dispersions and form a network which may help to maintain cell rigidity. These particles are divided into smooth- and rough-surfaced variants and are associated with lipid and protein synthesis respectively (Palade, 1955b).

These cytochondria, including the Golgi apparatus, are now the scene for current investigations in cellular pathology. It is possible to describe the mezhanisms of disease in terms of disordered particles and observe how alterations of particles in some instances participate in pathogenesis.

\section{Mitochondria in Disease}

The immediate concern with mitochondria in disease is the correlation of their morphological alterations with functional disturbances. The typical rodlet configuration of normal intracellular mitochondria has been determined by cinematography with phase microscopy (Harman, 1954 ; Frederic, 1958) and reaffirmed by electron microscopy for many tissues (Palade, 1952). Numerous investigators have established in vitro and in vivo that departure from this shape, by enspherulation or rarefaction, is a response te various stress agents (Harman and Feigelson? 1952 ; Cleland and Slater, 1953). More recently a comprehensive review of these investigations using electron microscopy confirmed the observations determined at the light level (Sjöstrand, 1956 ; Rhodin, 1954). The phenomena occurring within the cell in response to stress have been grouped as the process called "cloudy swelling," in which the most salient derangement is the distortion of mitochondrial morphology.

The fundamental participation of the mitochondria in the process of cloudy swelling was established by Anitschow and Aschoff in 1914, thus extending the work of Fauré-Fremiet (1910). Imposition of hyposmolarity, toxaemia, starvation, and ischaemia uniformly effect the same mitochondrial alteration and cloudy swelling. Later workers repeated the pioneer experiments and confirmed again the association of mitochondrial enspherulation and rarefaction with cloudy swelling (Zollinger, 1948). Fig. 8 is a replica of the cells depicted in Fig. 5 after the application of hyposmolar stress and transformation. Recently Opie (1948) demonstrated that not only does an increase of mitochondrial volume characterize cloudy swelling under hyposmosis but basophilic material disappears from the cytoplasm, presumably out of the ribonucleic acid particles. This 
Drochmans (1947) confirmed by chemical analysis. Zollinger (1950) reviews all the evidence for the major role of the mitochondria in cloudy swelling.

A major advance in cytological technique occurred when media were improved allowing morphologically intact mitochondria to be isolated from the cell (Dounce, Witter, Monty, Pate, and Cottone, 1955 ; Novikoff, 1956b ; Birbeck and Reid, 1956). The steady refinement of isolation methods has provided several media which satisfy most of the ultrastructural criteria of normal segregated particles. Moderate hyperosmolarity with selected non-electrolytes, careful $p \mathrm{H}$ adjustment, refrigeration, and elimination of noxious contaminating ions by chelation enable native fresh mitochondria to be obtained. Considerable analysis has emphasized the deleterious effects on mitochondrial morphology (Harman, 1956) of any departure from these restrictions. With native mitochondria so obtained it has been possible to elicit the phenomena of cloudy swelling in the free, uncontaminated

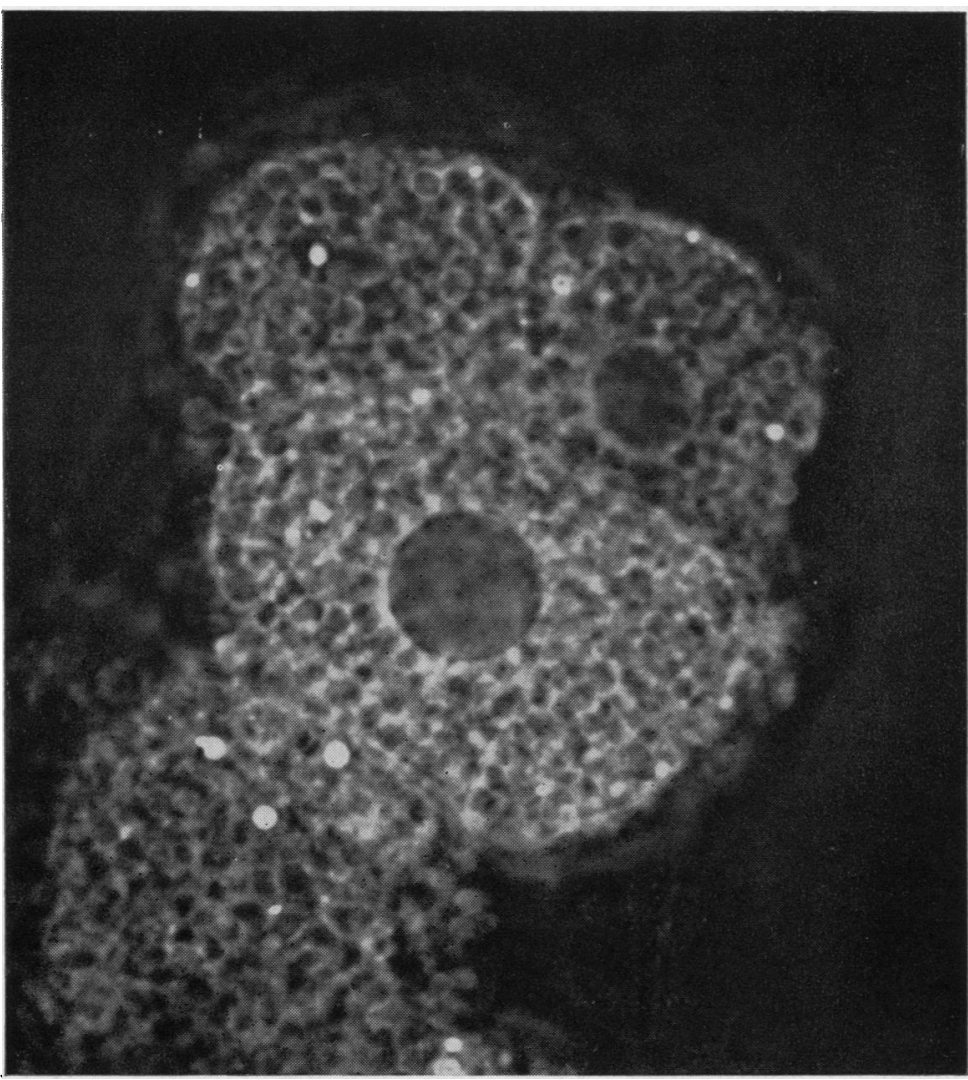

FIG. 8. -The identical cells illustrated in Fig. 5 are seen after brief exposure to deionized water at $25^{\circ}$. Slight swelling is obvious, with vesiculation and blurring of the inner structure. Contrast seems reversed although light contrast conditions still apply. $\times 1,500$. units.

The mitochondria isolated under ideal conditions are described as "resting" particles. So long as they remain in rodlet form, their metabolism and phosphate exchange is minimal. After variable periods of "ageing," even at low temperature, changes in form begin, and the metabolism of the integrated enzyme systems are more ungovernable when they are regarded as "aged" preparations, with the connotation of a specific morphological and metabolic deformity. The process of "ageing" may be accelerated by applying temperature gradients, osmolar variation, minute quantities of certain ions, e.g., $\mathrm{Ca}^{++}$, at levels below osmolar influence, and by mechanical agitation as well as by certain organic solvents. These are the various types of transforming agent and their overall effect is seen in the occurrence of mitochondrial swelling and the formation of distinctive spheres with crescentshaped marginal condensations. Fig. 9 shows mitochondria from skeletal muscle suspended in deionized water. Several reports have confirmed the sequence of events which lead to swelling and have established the alterations of hydration, dry weight, and optical density accompanying the change. Ionic radiation has a similar effect (Fig. 9a).

The morphological alterations distinguished above under the impact of transforming agents are attended by profound disturbance in the mitochondrial metabolic activities. It has been well confirmed that the Krebs's cyc'e operates as an integrated system within the mitochondria, and is facilitated by the intimately associated KeilinHartree electron chain which is confined to the mitochondria. It is thus that the sequential oxidation of the moieties of the cycle are concatenated with the traversing of the electron chains and the development of high energy phosphates in the nucleotide pools which the mitochondria contain (Figs. 10, 10a). This high energy, especially as adenosine triphosphate 

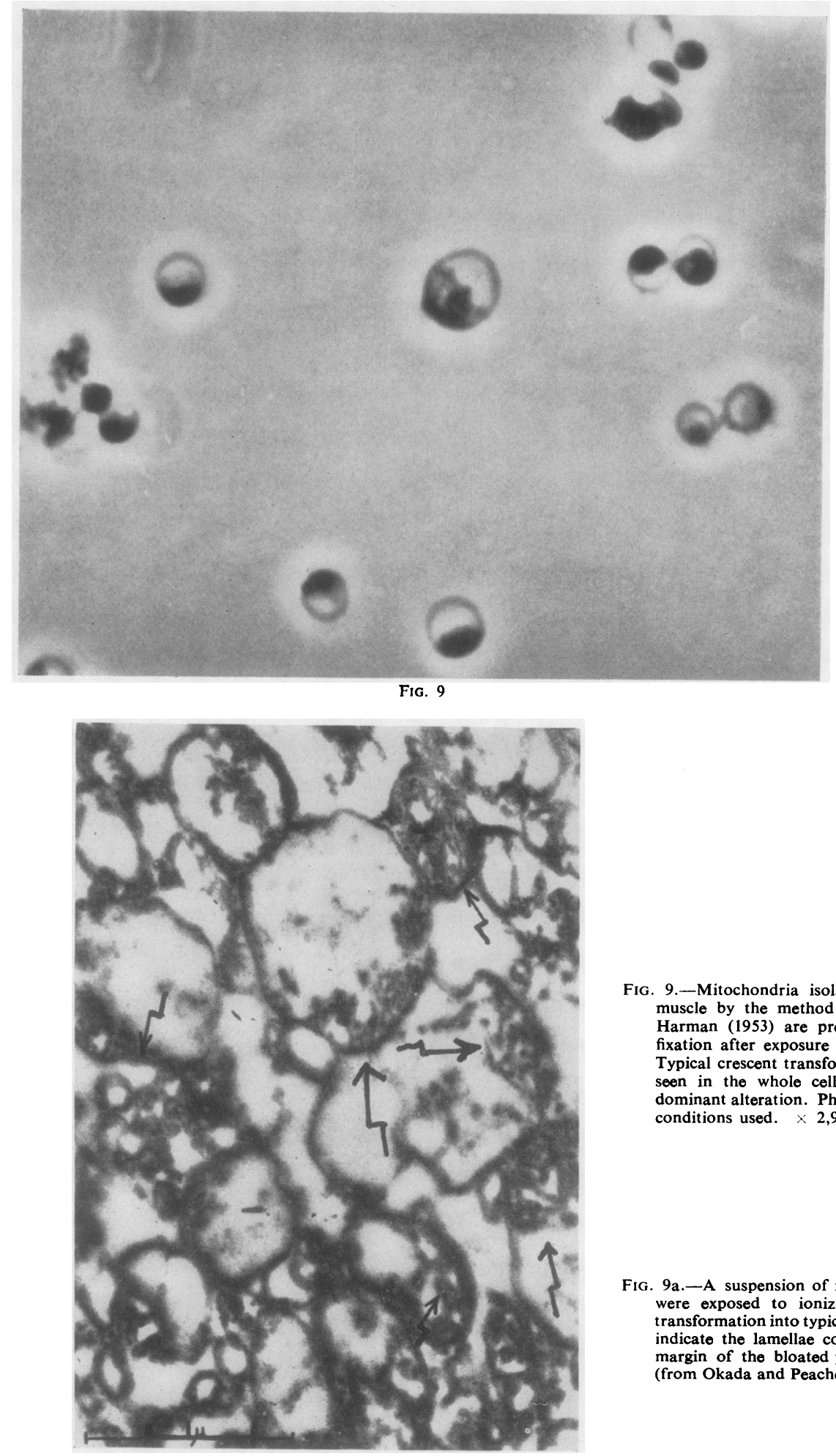

FIG. 9.-Mitochondria isolated from skeleta muscle by the method of Kitiyakara and Harman (1953) are preserved by osmium fixation after exposure to deionized water. Typical crescent transformation, which was seen in the whole cell of Fig. 1, is the dominant alteration. Phase contrast, dark $\mathrm{L}$ conditions used. $\times 2,900$.

FIG. 9a.-A suspension of mitochondria which were exposed to ionizing radiation, with transformation into typical crescents. Arrows indicate the lamellae concentrated along a margin of the bloated particles. $\times 22,000$ (from Okada and Peachey, 1957).

FIG. 9a

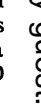




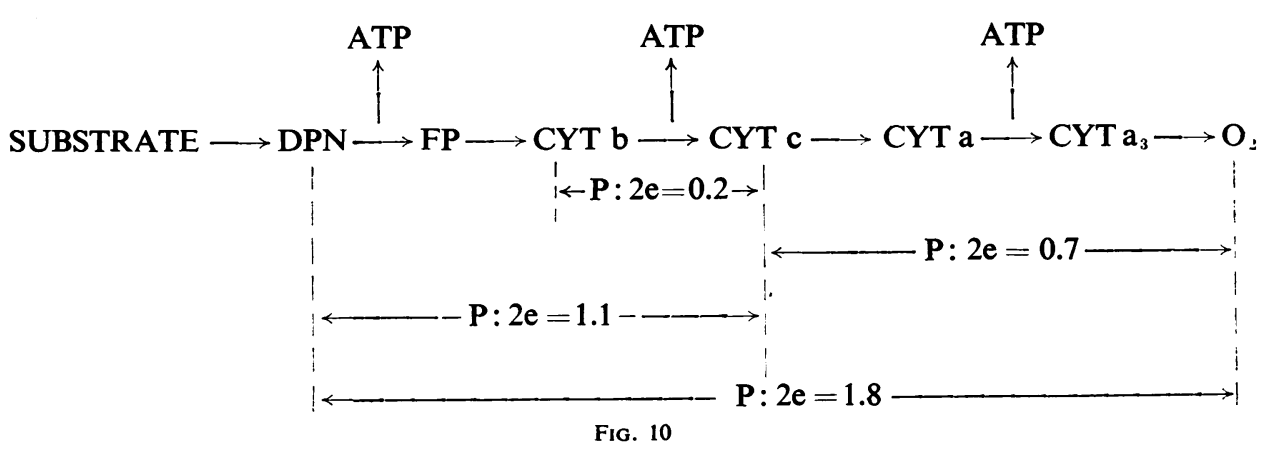

FIG. 10.-This is illustrative of the established sequence of the KeilinHartree electron chain, with the points where high energy is tapped off into ATP traps, which are confined within cross-over sites.

FIG. 10a.-The nucleotide pool within the mitochondria is essentially a system employing ADP as acceptor for high-energy phosphate, with some myokinase participation. Sites of action of ATPase, DNP, and synthesis are suggested.

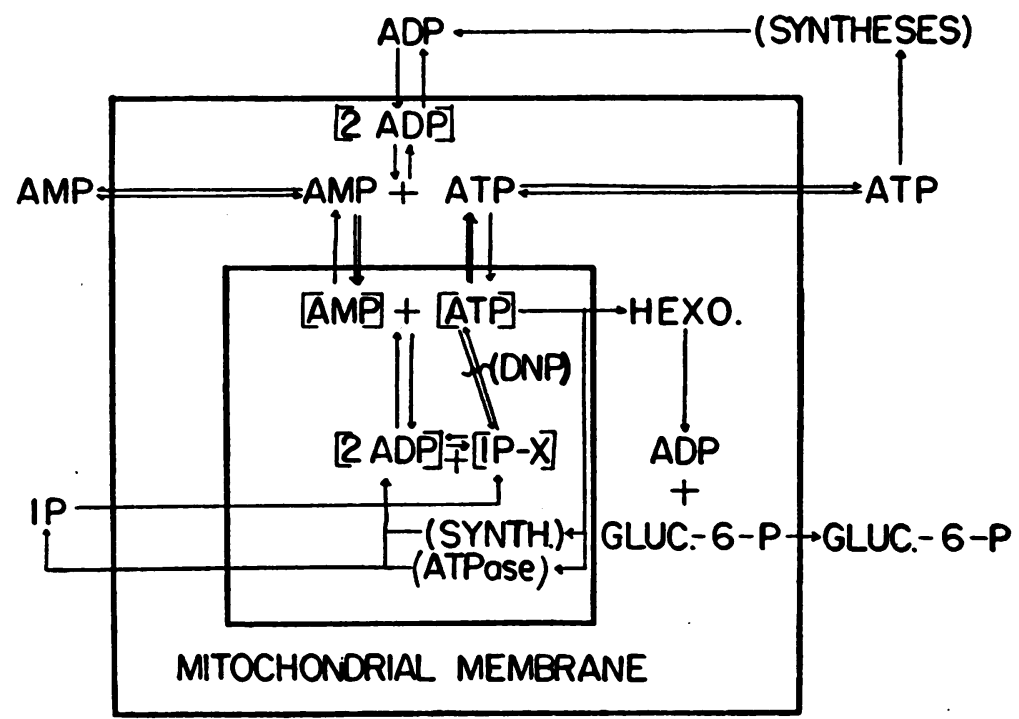

FIG. 10a

(although it may take other forms), is available in the first instance for the maintenance of mitochondrial integrity itself and also for the provision of energy to maintain other structures and functions of the cell. Ball and Barrnett (1957) have allocated the disposition of separated oxidase systems from the cycle to the inner membrane fractions derived from isolated mitochondria, and Devlin and Lehninger (1956) have obtained phosphorylation with such fractions. Hatefi and Lester (1958) have detached heavy and light lipid components from the heart mitochondria and detected organization of an enzyme sequence which permits phosphorylation by the separated oxidases, e.g., the alphaketoglutaric oxidase group.

The distortion of mitochondrial morphology has therefore been associated primarily with a disruption of the organized sequence of the Krebs's cycle and with the augmentation of unrestricted oxidation of metabolites. This chaotic state is not attended by phosphorylation, so that the process of transfer of energy into the nucleotide reservoirs is impaired and the energy level of the units is depleted. The decrease in available high energy adenosine triphosphate permits further swelling and dissolution of the units into hulls which are beyond reconstruction. Both Raaflaub (1953) and Ernster (1956) believe that adenosine triphosphate fits into the structure whereas Harman and Feigelson (1952) prefer to regard it as a source of energy for structural re-synthesis, as for hydrogen bonding. If this happens within the cell the processes dependent on the flow of high energy from the mitochondria are in abeyance, and if they are critical to cell economy cell death is inevitable.

The phenomenon of cloudy swelling and mitochondrial structural deformity is not a simple matter of separating oxidation and phosphorylation. The gamut of phosphoroclastic enzymes 


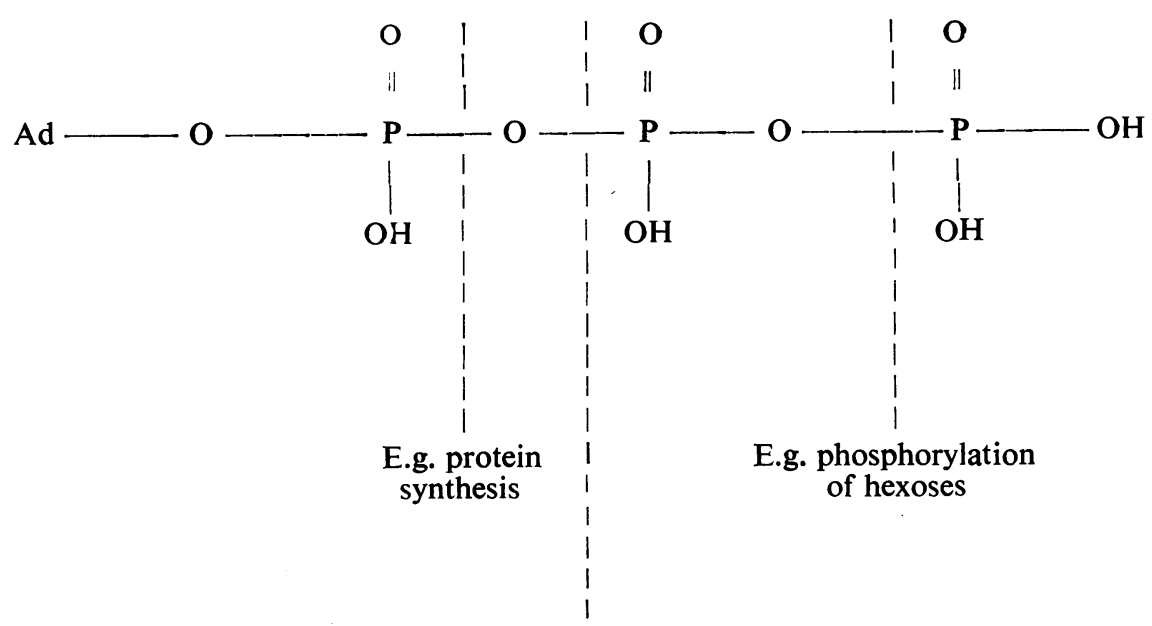

E.g. nucleic

acid synthesis

FiG. 11.-The sites of utilization of the high energy phosphate and splitting of PO bonds is shown, knowing that the same enzymes may employ $\mathrm{H}_{2} \mathrm{O}$ as well as the specific receptors indicated, when organization is deranged (cf. Grabe, 1958).

which are galvanized into motion have an especial propensity and specificity for cleaving nucleotides concerned with electron and high energy phosphate transfer. The adenosine triphosphates, pyrophosphatases, and phosphatases operate at several levels and strike at the points concerned in the phosphorylation processes designed for the anabolic cellular functions. When disturbance occurs in normal concatenated enzyme cofactor associations and structural deformity ensues, e.g., with osmotic swelling, the enzymes capable of utilizing the P-O bonds in adenosine triphosphate for protein synthesis, nucleic acid formation, and hexose phosphorylation, among other syntheses, are labilized and split the bonds at the appointed site without transfer of energy from catabolism to anabolism (Grabe, 1958). Fig. 11 depicts the operative sites in the adenylpyrophosphate molecule for the various clastic enzymes. For example, in protein synthesis, under the agency of an activating enzyme, the pyrophosphate is sheared off and the adenosine monophosphate fragment united with the amino-acid to yield, for instance, adenylleucine. The net result of such a reversal of enzyme function is the literal piecemeal tearing apart of the cell unless some portion of the synthetic mechanism survives to compensate adequately. Since the mitochondria and lysosomes also are rich in catheptic enzymes, lysolecithin, and other lytic factors, it is remarkable that cloudy swelling is considered as reversible. To my knowledge no one has determined the survival of cells submitted to cloudy swelling, and most observations have been made on post-mortem samples. In vitro the state of the mitochondria equivalent to cloudy swelling is not reversible, because of gross fracture of structural units (Kaltenbach and Harman, 1955) and depletion of ribonucleic acid constituents (Fig. 12).

\section{Action of Bacterial Toxins}

Because of the especial concentration of oxidative and phosphorylating systems in mitochondria the metabolic vulnerability of the cell is often largely dependent upon them. This has provided several groups of workers with a focus for their investigations of various diseases, especially the mechanism of toxicity characteristic of certain infectious diseases. The Italian school of Fonnesu and Severi (1956) has accumulated evidence by in vivo studies and with mitochondria isolated from animals intoxicated with diphtheria toxin that the specific action of the active component is against the mitochondria with cloudy swelling, lowering of oxidative phosphorylation and $\sim P$ reserve. The same effect is observed after injections of $S$. typhimurium and other bacterial extracts. Pappenheimer and Hendee (1947) have suggested that in diphtheria the toxin is the protein component of cytochrome $\mathrm{b}$ manufactured by $C$. diphtheriae. This is in effect an elaboration of a succinic acid dehydrogenase, which is suspected of penetrating into the mitochondrial succinoxidase system in heart muscle and kidney and of 



FIG. 12.-The mitochondria depicted were isolated in isosmolar sucrose which were exposed to short periods of deionized water treatment, then to thermal activation. These units then placed in hyperosmolar solution shrank, but persisted as elongated threads. (1) Original ; (2) $30^{\prime}$ in $\mathrm{H}_{2} \mathrm{O}$; (3) $120^{\prime}$ in $\mathrm{H}_{2} \mathrm{O}$; (4) in isosmolar sucrose again. The original compact form was not resumod. $\times 11,000$. 
displacing the normal electron flow. Impedance of the integrated system interferes with total oxidative phosphorylation, encourages $P$ pools to fall, and allows dispersal of mitochondrial structure or the occurrence of cloudy swelling. Although Pappenheimer and Williams (1952) have demonstrated the coincidence of the action of diphtheria toxin with the time of the appearance of cytochrome $b$ in larvae, problems concerning the production of toxin by the bacterium are not yet clear enough to identify the toxin with the cytochrome protein. Furthermore, cytochrome c is not part of the electron path of diphosphopyridine nucleotide-dependent oxidases. Waksman, Adams, and Mansmann (1957) suggest that since the toxin interferes with phosphorylation in several types of cell, it may cause diphtheritic polyneuritis by such injury to the Schwann cells.

That several other bacterial products exert their action on mitochondria is illustrated in the following two examples. A most potent toxin from $\mathrm{Cl}$. welchii is the alpha-toxin or lecithinase, which has the property of splitting phosphocholine from lecithin and displacing the compound from its structural position. Another enzyme, phospholipase, which occurs in snake venoms, splits the unsaturated fatty acid from lecithins and elaborates a factor called lysolecithin, which in itself has a lytic action on lipid-protein membranes. These enzymes from animal and bacterial sources have a dual action on mitochondria as the toxins directly dissolve the laminated and organized structure of the particles by destroying the lipoprotein mosaic (Nygaard, Dianzani, and Bahr, 1954) and simultaneously they hasten the swelling by inactivating a lipid containing electron transport factor located in the succinoxidase system between the cytochrome b and cytochrome c components (Nygaard, 1953). Cryptically situated lysins (Tyler, 1951) and enzymes of similar character are distributed in most animal cells and may be activated to interfere with mitochondrial permeability (Witter and Cottone, 1956). On the other hand, as a second example, certain streptococci of the $\beta$-haemolytic type produce a lysin which may profoundly affect the mitochondrial system in a different manner. Carlson, Kellner, and Bernheimer (1956) have shown that streptolysin-O from filtrates of streptococcal supernatants has the selective capacity of inhibiting the oxidative metabolism of cardiac mitochondria. Further examination of this phenomenon verifies that the inhibition is due to a streptococcal diphosphopyridine nucleotidase (Carlson, Kellner, Bernheimer, and Freeman, 1957) which destroys the co-enzyme diphosphopyridine nucleotide essential for the function of several oxidases of the mitochondria, which are therefore attacked with remarkable specificity. A similar enzyme has been detected in plague toxin (Ajl, Rust, Woebke, and Hunter, 1956), which differs slightly from the streptococcal enzyme by splitting the diphosphopyridine nucleotide at the phosphate rather than the nicotinamide-ribose junction. The importance of diphosphopyridine nucleotidase in its pathogenesis and virulence is suggested by the correlation of its activity with the leucocidal and myocardial damaging capacity of the organism (Bernheimer, Lazarides, and Wilson, 1957 ; Kellner, Bernheimer, Carlson, and Freeman, 1956).

\section{Organic Toxic Compounds}

Among a plethora of noxious organic chemical agents which can induce cloudy swelling, carbon tetrachloride has received exceptional attention, together with the related compound, chloroform. Several workers have employed it for the elucidation of phenomena concerned in cellular injury and use it as a prototype reaction. Christie and Judah (1953) have assessed the action as a direct structural disruption of the mitochondrial population of the cell, with disorganization of the integrated enzyme systems comprising the tricarboxylic acid cycle and an accompanying loss of co-enzymes, especially di- and triphosphopyridine nucleotides. The co-enzyme splits away at a different rate from the various oxidases, an observation which agrees with the opinion by Huennekens and Green (1950) that various enzyme systems have different tenacities for their co-enzymes. A specific block has been detected, moreover, in the system which can be explained on the basis of derangement of the normal sequence of enzyme activity. The more recent observations of Recknagel and Malamed (1958) contend that carbon tetrachloride obliterates a normal mitochondrial permeability barrier and so produces swelling, and the other consequences follow this initial change. The displacement of the co-enzyme may be the prime insult in both instances, and it would be desirable to extend the observations concerning the ketoglutarate block to determine its reversibility with appropriate co-enzyme fortification. Before accepting the thesis that the carbon tetrachloride acts directly on the mitochondrial structure it is necessary to evaluate the observations of Theirs, Reynolds, and Vallee (1958) on ion changes in mitochondria from $\mathrm{CCl}_{4}$-intoxicated animals. There is a 16-fold rise in calcium ions immediately, 
accompanied by a sharp fall in potassium. The total ion binding and content is constant. It may be, therefore, that $\mathrm{CCl}_{4}$ destroys normal cell membrane permeability and allows calcium to sweep into the cell with its deleterious actions on mitochondrial form and function, since $\mathrm{Ca}^{++}$is an established mitochondrial toxin (Ernster and Löw, 1955 ; Slater and Cleland, 1953). They also noted that simultaneously there was uncoupling of oxidative phosphorylation with all substrates of the Krebs's cycle used, although some restoration of function is possible with added diphosphopyridine nucleotide and cytochrome c. It appears likely, therefore, that the damage is similar to thio-acetamide intoxication as determined by Gallagher, Gupta, Judah, and Rees (1956).

This type of experiment leads to a consideration of the metabolic accumulations which may attend stress damage to mitochondria. It is imperative to introduce a concept at this juncture to clarify certain lesions in the cell ultrastructure which are at the junctional site of molecular structure and function. It may be feasible to group together all those lesions which lie at the border of fine structure and metabolism and are characterized by the accumulation of the various metabolites along the pathways of the organized systems. Since amassing of intermediates in unusual quantities may have injurious consequences for the system, it constitutes a special type of metabolic lesion. A good example is the lesion induced by fluoro-acetate intoxication (Liébecq and Peters, 1949) in which large amounts of citrate are dammed within the mitochondrion associated with undesirable chelation reactions. A still more naturally likely variety is demonstrated by Montgomery and Webb (1956) with parapyruvate, which is a naturally occurring dimer incidental to simple accumulation of pyruvate. It powerfully inhibits oxidative decarboxylation of oxyketoglutarate, to which it has structural similarity. It has been suggested that this similarity allows the parapyruvate to occupy the ketoglutarate binding site on the mitochondrial oxidase, and so taking part in the reaction sequence, the formation of a stable cirtramalyl derivative with co-enzyme-A or lipoic acid, and the titration out of the cofactor, so completely blocking the cycle. Examination in our laboratory of the mitochondria under the influence of parapyruvate block demonstrated a typical bizarre swelling characteristic of that found with several chelating agents and observed with cloudy swelling (Harman, 1958). It is conceivable that numerous metabolites may behave like pyruvate under the influence of genetic and toxic agents and allow injurious alternative polymerizations and racemizations to interpose metabolic blocks. The process may be called " parametabolism," without excluding its intervention to some extent in normal processes. One is thus led to consider, for example, whether the myohaemoglobinuria, peculiar to horses and some humans, which is preceded by massive glycolysis of muscle glycogen, may be caused by an accumulation of pyruvate rather than lactate and the formation of overwhelming volumes of parapyruvate which interfere with muscle metabolism so acutely as to cause structural collapse of the myofibres.

It has been conventional to follow any discussion of the phenomenon of cloudy swelling with that of fatty degeneration, thus suggesting that they are connected. This respected tendency rests on the claim that more potent noxious agents press the cell beyond cloudy swelling into fatty changes. The frequent association of the two events allows of some belief in this opinion. It is more apposite, however, to consider at this juncture whether the bloated mitochondria of cloudy swelling are converted directly to fat vacuoles or some deviation of function allows accumulation of the fat within the hyaloplasm. Some observers have separated the fat particles from fatty livers and obtained mitochondrial enzymes among them, but the unavoidable comminution of mitochondria which accompanies the homogenization technique, though small, may account for this distribution, and these workers are therefore cautious in interpreting their results. On the other hand, it is expected that since the fatty acid oxidase system is the most sensitive of all the oxidases the mitochondrial derangements are conducive to the appearance of particulate fat in the cytoplasm. The activation of fatty acid oxidation normally requires a ready source of adenosine triphosphate either from an available nucleotide pool or an actively operative mitochondrial oxidative system. Dianzani (1954) has assembled data which point to depression of the $\mathrm{P} / \mathrm{O}$ ratio with substrates requiring diphosphopyridine nucleotide, such as malate, glutamate, pyruvate, and ketoglutarate, by mitochondria obtained from fatty livers developed by injection of steatogenic poisons or feeding choline-deficient diets. He expressed the opinion that the low ratios were due to the loss of phosphorylative abilities as a consequence of morphological degenerative processes. Both co-enzymes I and II and cytochrome $\mathrm{c}$ are considerably reduced in the fatty livers (Dianzani, 1955 ; Dianzani and Viti, 1955), and these alterations are accompanied by a sharp decrease in the adenosine triphosphate 
content of the mitochondria (Dianzani, 1957). A most significant finding has been the depletion of CoA content (Severi and Fonnesu, 1956). The two most important compounds, adenosine triphosphate and CoA, are thus found to be reduced under conditions of accumulated pathological fat in the liver. It is significant that both are implicated in the fatty acid activating system. But whether the activating system affected is mitochondrial bound or extramitochondrial is not decided. In correlation with these observations it has been shown that the mitochondria from diabetic livers have significantly decreased oxygen uptake, phosphorylation, and $\mathrm{P} / \mathrm{O}$ ratios during oxidation of pyruvate (Vester and Stadie, 1957). The livers from the animals were markedly fatty, whether as cause or effect of the oxidative distress is debatable. In view of recent findings that the essential fatty acids are required for structural stability and phosphorylative efficiency of mitochondria, it is necessary to keep in mind that drastic morphological and functional changes may be precipitated by rapid exhaustion of these sparse compounds (Levin, Johnson, and Albert, 1957).

\section{Hormonal Control}

The problem of abnormal control of tissue metabolism by hormones has been best exploited with excess thyroid activity. Total energy output is closely modified by graded stimulus of thyroid hormone and its derived active products. Only recently has an approach been achieved to the exact site of cellular activity under the influence of this hormone. From the early work of Maley and Lardy (1953) it was proposed that the active hormone and thyroxin might produce their effect by uncoupling oxidative phosphorylation, which in essence signified a purposeless oxidation of metabolites. DuToit (1952) had reached the conclusion that thyrotoxicosis is related not to control of individual enzymes but to an effect on the mitochondrion in the regions where respirat:on chains are coupled to the production of high-energy phosphate bonds. The subsequent investigations by Tapley and Cooper (1956) confirmed this view and indicated that the immediate action of the thyroxin and related active compounds was to increase mitochondrial volume and derange the mitochondrial processes concerned with control of fluid and electrolyte balance within the particle. These effects occur at thyroxin levels considerably below those required to uncouple oxidative phosphorylation. There is no question indeed but that mitochondrial morphology is considerably changed from normal in both hypo- and hyper-thyroid states (Abei and Abelin, 1953). It is suggested that the hormone performs its metabolic regulation by directing the attachment of critically placed magnesium ions which are known to stabilize mitochondrial configuration. One group has compared thyrotoxicosis with magnesium deficiency clinically and further demonstrated identical $\mathbf{P} / \mathrm{O}$ ratios in heart mitochondria from both thyrotoxic and magnesiumdeficient animals. It is known that magnesium has power to reverse the swelling potency of thyroxin in isolated mitochondria, and that hypothyroid patients excrete excessive amounts of magnesium after receiving thyroxin (Tapley, 1955). It may be suggested that the states of euthyroidism and departures from it into conditions of hypo- and hyper-thyroidism are mainly dependent on the balanced magnesiumthyroid control of mitochondrial structure and through this upon the rate of oxidative metabolism. Further support for this relationship is provided by the series of observations which establish a connexion between the stability of mitochondrial morphology and the binding of the magnesium and manganese ions by the mitochondria (Hunter and Ford, 1955 ; Bartley and Amoore, 1958), so that agents freeing them alsoo loosen the mitochondrial hull and allow swelling and leakage of nucleotides to follow. The careful studies of Raaflaub (1953) and others on the stabilizing influence of adenosine triphosphate indicate that such ions are an essential coconstituent for the most satisfactory system. It is correct to presume that potassium binding is also a structural feature, which permits contractual relations between the mosaic of enzymes which operate in the oxidative phosphorylative mechanisms, whether the process is engaged at the total particle level or in subunits derived by special fractionation techniques (Gamble, 1957). The bound potassium therefore enters into the scheme for thyroxin activation. A preliminary report by Panagos, Beyer, and Masoro (1958) has shown that liver mitochondria are stress points in animals exposed to cold, and explain the resulting uncoupling of oxidative phosphorylation by intermediate action of increased thyroid secretion. The studies of cardiac mitochondria by Strawitz and Hift (1956) and by Hift and Strawitz (1958) with animals in irreversible haemorrhagic shock have demonstrated profound morphological, metabolic and chemical alterations. Mediation by hormonal stress, including thyroid excess, is likely. As yet no examination of mitochondria under the influence of thyroid hormones has been made by 
electron microscopy, though such a study is now an essential part of the survey at electron level.

Since the modus operandi of thyroid hormone and analogues has revolved around mitochondrial structure, it is pertinent at this juncture to explore a range of pharmacological and toxic compounds which affect metabolism at the same point of stress. A recent interpretation of the action of dinitrophenol, which stimulates oxidations and impairs phosphorylations, has attached considerable importance to the morphological deformities induced by dinitrophenol (Kaltenbach and Harman, 1955). Other investigations designed to clarify participation of a complex interrelation between $p \mathrm{H}$, metal ion complexon formation, and thermal reactivity in adenosine triphosphatase activity have taken into consideration the importance of alteration in mitochondrial age (or structure) as a factor contributing to the shift from a mechanism which transfers energy through a high energy intermediate to adenosine diphosphate to one which allows the intermediate to dissipate before the transfer is effective (Kielley and Bronk, 1958). Damage is extended by the fall in $\sim P$ and the activation of adenosine triphosphatase which is normally cryptic, so that a rapid mitochondrial disintegration ensues and oxidative metabolism is unfettered. The attack by dinitrophenol on the mitochondrial phosphorylation sequence is thus a model of the basic pattern of injurious interference with this fundamental metabolic pathway. A wide variety of dyes and biological compounds have been so analysed (Harman and Feigelson, 1952).

Perhaps one of the most interesting studies has been on the behaviour of mitochondria and respiring tissue under the influence of excessive concentrations of several naturally occurring pigments. It was shown by Zetterström and Ernster (1956) that unconjugated bilirubin in quantities approximating the level seen in hyperbilirubinaemic syndromes associated with haemolytic disease of the newborn (Ernster, Herlin, and Zetterström, 1957) have a decisive uncoupling action on liver and brain mitochondria. The bilirubin causes not only a severe inhibition of the phosphorylation but also depresses oxidation, and manifests this in both liver and brain mitochondria. This property of bilirubin, in unconjugated form, has been linked by several groups with the occurrence of kernicterus, or, as it may be more accurately called, if the relationship holds fast, "bilirubin encephalopathy." Biliverdin and the conjugated bilirubin are incapable of uncoupling. These observations
TABLE I

EFFECT OF HAEMATOPORPHYRIN ON LIVER MITOCHONDRIA

\begin{tabular}{|c|c|c|c|c|}
\hline \multicolumn{3}{|c|}{ System } & P'O & $\begin{array}{c}\text { Cytology } \\
(\text { Crescents \%) }\end{array}$ \\
\hline Glutamate & $\begin{array}{l}\text { + Albumin } 3.5 \% \\
+ \text { Haematoporphyrin } \\
+ \text { Both } \quad . .\end{array}$ & $\begin{array}{l}\cdots \\
\cdots \\
\cdots\end{array}$ & $\begin{array}{l}3 \cdot 0 \\
28 \\
0 \\
0 \cdot 9\end{array}$ & $\begin{array}{l}\text { Normal } \\
\text { Normal } \\
\text { All degenerate } \\
50 \% \text { degenerate }\end{array}$ \\
\hline Malate & $\begin{array}{l}+ \text { Albumin } 3 \cdot \dot{5} \% \\
+ \text { Haematoporphyrin } \\
+ \text { Both }\end{array}$ & $\begin{array}{l}\cdots \\
\cdots \\
\cdots\end{array}$ & $\begin{array}{l}3 \cdot 0 \\
3 \cdot 1 \\
0 \\
2 \cdot 43\end{array}$ & $\begin{array}{l}\text { Normal } \\
\text { Normal } \\
\text { All degenerate } \\
21 \% \text { degenerate }\end{array}$ \\
\hline
\end{tabular}

have been repeated with similar results and the range of substrates confirmed. It has been found, however, that inclusion of albumin with the mitochondria provides appreciable protection to the oxidative phosphorylation (Harman, 1958). Furthermore, bearing in mind that metabolic products or excessive accumulation of haemoglobin precursors may be injurious, the action of haematoporphyrin on liver mitochondria was determined. It provoked (Table I) morphological changes similar to cloudy swelling, uncoupled oxidative phosphorylation, and yet prevented the appearance of adenosine triphosphatase activity. The uncoupling activity was moderately reversed by albumin, as in the case of bilirubin excess. This

TABLE IIA

EFFECT OF DINITROPHENOL ON OXIDATIVE PHOSPHOR YLATION IN ISOLATED MITOCHONDRIA WITH AND WITHOUT ALBUMIN Substrate: succinate.

\begin{tabular}{|c|c|c|c|c|c|c|}
\hline \multirow[b]{2}{*}{ Additions } & \multicolumn{3}{|c|}{ Without Albumin } & \multicolumn{3}{|c|}{ With Albumin } \\
\hline & $\underset{\mu \mathbf{M}}{\triangle \mathbf{P}}$ & $\begin{array}{l}\triangle \mathrm{O} \\
\text { Micro- } \\
\text { atom.s }\end{array}$ & $\mathbf{P}: \mathbf{O}$ & $\underset{\mu \mathbf{M}}{\triangle \mathbf{P}}$ & $\begin{array}{l}\triangle \mathrm{O} \\
\text { Micro- } \\
\text { atoms }\end{array}$ & $\mathbf{P}: \mathbf{O}$ \\
\hline $\begin{array}{l}\text { None } \ddot{1} 10 \\
\text { DNP M } / 100 \ldots \\
\text { DNP } M / 1,000 \ldots\end{array}$ & $\begin{array}{r}19 \cdot 4 \\
3 \cdot 8 \\
1 \cdot 2\end{array}$ & $\begin{array}{r}11 \cdot 3 \\
4 \cdot 9 \\
9 \cdot 5\end{array}$ & $\begin{array}{l}1 \cdot 7 \\
0 \cdot 78 \\
0 \cdot 12\end{array}$ & $\begin{array}{r}25 \cdot 6 \\
1.8 \\
29.8\end{array}$ & $\begin{array}{r}13 \cdot 0 \\
7 \cdot 5 \\
14 \cdot 2\end{array}$ & $\begin{array}{l}1 \cdot 9 \\
0 \cdot 24 \\
2 \cdot 09\end{array}$ \\
\hline
\end{tabular}

TABLE IIB

EFFECT OF GRADED LEVELS OF DINITROPHENOL ON OXIDATIVE PHOSPHORYLATION IN ISOLATED MITOCHONDRIA WITH AND WITHOUT ALBUMIN Substrate: oxyglutarate.

\begin{tabular}{|c|c|c|c|c|c|c|}
\hline \multirow[b]{2}{*}{ Additions } & \multicolumn{3}{|c|}{ Without Albumin } & \multicolumn{3}{|c|}{ With Albumn } \\
\hline & $\underset{\mu \mathbf{M}}{\triangle \mathbf{P}}$ & $\left|\begin{array}{c}\Delta \mathrm{O} \\
\text { Micro- } \\
\text { atoms }\end{array}\right|$ & $\mathbf{P}: \mathbf{O}$ & $\underset{\mu \mathbf{M}}{\Delta \mathbf{P}}$ & $\left|\begin{array}{c}\wedge \mathrm{O} \\
\text { Micro- } \\
\text { atoms }\end{array}\right|$ & $\mathbf{P}: \mathbf{O}$ \\
\hline 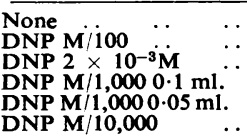 & $\begin{array}{r}20.4 \\
+1.8 \\
+3 \cdot 7 \\
7 \cdot 6 \\
10 \cdot 4 \\
17 \cdot 2\end{array}$ & $\begin{array}{l}9 \cdot 0 \\
3 \cdot 5 \\
4 \cdot 2 \\
9 \cdot 0 \\
9 \cdot 4 \\
8 \cdot 79\end{array}$ & $\begin{array}{l}2 \cdot 2 \\
-\overline{1} \\
0 \cdot 84 \\
1 \cdot 1 \\
1 \cdot 9\end{array}$ & $\begin{array}{c}22 \cdot 8 \\
+1 \cdot 02 \\
20 \cdot 4 \\
19 \cdot 6 \\
21 \cdot 2 \\
20 \cdot 0\end{array}$ & $\begin{array}{r}12 \cdot 3 \\
4 \cdot 2 \\
8 \cdot 8 \\
14 \cdot 6 \\
14 \cdot 0 \\
13 \cdot 2\end{array}$ & $\begin{array}{l}1 \cdot 9 \\
2 \cdot 3 \\
1 \cdot 3 \\
1 \cdot 5 \\
1 \cdot 5\end{array}$ \\
\hline
\end{tabular}


effect of albumin is at the moment under scrutiny (Table IIA, IIB), and it has been found capable also of neutralizing the uncoupling action of dinitrophosphatase on phosphorylation (Clarke, 1958). The neuronal damage in both these derangements of bile accumulations and abnormal porphyrin metabolism are explicable on the mitochondrial scale, but caution is advocated in view of the decidedly protective mediation of serum albumin at physiological levels.

\section{Vitamin Control}

For many years a relation between the tocopherols and muscle diseases, especially the dystrophies, has been favoured but fortified with only marginal evidence, which was often contradictory. The recent experiments by Nason, Donaldson, and Lehman (1957) have offered an escape from the dilemma of conflicting results and supplied a site for the intervention of the vitamin in the metabolism of muscle and other tissues. It is obvious from extraction studies with both homogenates and purified mitochondria suspension that the alphatocopherol is committed to participation in the respiratory chain. Removal of a lipid component from particulates of rat skeletal muscle, which corresponds approximately with a sarcosomal-mitochondrial admixture (Kitiyakara and Harman, 1953), interfered electively with electron transport at the site of disphosphopyridine-cytochrome c reductase activity. Although the enzymatic activity of the particulate DPNH-cytochrome c reductase is re-established by the addition of alphatocopherol, or the residue of the iso-octane extract, it can also be reconstituted by fortifying the extracted particles with $1 \%$ serum albumin. Since neither the extract nor the albumin contains alphatocopherol, the full composition of the co-factor is not defined and may be a complex containing alphatocopherol. Bouman and Slater (1957), however, established that an active Keilin-Hartree suspension of heart muscle, which is mainly composed of mitochondrial fragments, contains significant quantities of alphatocopherol, and reached the result that it is all mitochondrial bound. Slater (1958) suggested that it or a derivative quinone is an essential link between oxidation and phosphorylation. Further studies by the same group challenged the specificity of the tocopherol at enzyme level and postulated that the compound favourably reorientated physical properties (structure) dispersed by iso-octane elution. In accordance with the findings of Martius (1956), who suggested that the defect of vitamin $\mathrm{E}$ undermines oxidative phosphorylation, the above close ana- lyses move the problem of muscular dystrophy closer to a solution.

The series of reactions as postulated from sundry studies depicts the hypothetical phosphorylation mechanism normally linked to the electron chain at several established sites (equations 1-4). It is

$$
\begin{aligned}
& \mathrm{AH}_{2}+\mathrm{B}+\mathrm{I} \rightleftharpoons \mathrm{A} \sim \mathrm{I}+\mathrm{BH}_{2} \ldots \ldots \ldots \ldots \ldots(1) \\
& \mathrm{A} \sim \mathrm{I}+\mathrm{X} \rightleftharpoons \mathrm{A}+\mathrm{X} \sim \mathrm{I} \quad \ldots \ldots \ldots \ldots \ldots \ldots(2) \\
& \mathrm{X} \sim \mathrm{I}+\mathrm{P}_{\mathrm{i}} \rightleftharpoons \mathrm{X} \sim \mathrm{P}+\mathrm{I} \ldots \ldots \ldots \ldots \ldots \ldots(3 a) \\
& \mathrm{X} \sim \mathrm{P}+\mathrm{ADP} \rightleftharpoons \mathrm{X}+\mathrm{ATP} \ldots \ldots \ldots \ldots \ldots(3 b) \\
& \mathrm{X} \sim \mathrm{I}+\mathrm{H}_{2} \mathrm{O} \_(\mathrm{DNP})
\end{aligned}
$$

conceivable that the deficiency of tocopherol or a like quinone effects structural damage to the mitochondrion so as to promote hydrolysis of $\mathrm{X} \sim \mathrm{I}$ A loss of respiratory control and lowering of $P / O$ ratios would ensue, and the action in this instance would simulate that of dinitrophosphatase. It has been suggested alternatively that the quinone is actually $X$, although this is a less acceptable theory, and that its absence will allow accumulatiom of $A \sim I$ which may suffer hydrolysis by an altere nate mechanism, whereby oxidation of the sub strate is unimpaired but the phosphorylation is restricted. Such a view would account suitably for rapid exchange of ${ }^{18} \mathrm{O}$ between water and $\mathrm{PO}_{4}$, the inorganic phosphate of the system (Boyer). Recent analyses have indicated that the quinone functioning in the system may not be alphatocopherol but another compound designated as Q 275 (mitoquinone) by Crane, Hatefi, Lester, and Widmer (1957) and as ubiquinone by Festenstein, Heaton, Lowe, and Morton (1955). It is apparent from the studies by Slater (1958) that the bulk of the quinone in heart mitochondria occurs as ubiquinone or mitoquinone. Other workers (Hatefi, Lester, and Ramasarma, 1958) have reported in preliminary observations that the mitochondrial $\frac{}{3}$ bound mitoquinone is rapidly reduced by suc- $D$ cinate, DPNH, hydroxybutyrate, and diphospho- 으․ pyr:dine nucleotide-dependent substrates of the $N$ Krebs's cycle, with specific inhibition by antimycin for succinate and amytal inhibition for the other 0 substrates. Furthermore ubiquinone was able to $\mathrm{N}$ restore activity to iso-octane-extracted particles. These findings favour the opinion that the quinone 0 may be $\mathrm{X}$ in the phosphorylation scheme above. In either case the participation of the vitamin or $\stackrel{\mathscr{C}}{-}$ its derivative in the metabolic pathway empha- $\frac{T}{0}$ sizes its critical role in the maintenance of cell structure. Other workers concerned with the 
disposition of energy generating and transport systems in the muscle cell had proposed that the critical lesion was to be sought primarily in the mitochondrial system of integrated enzymes (Harman, 1955). It is also worthy of mention at this juncture that several teams of investigators have reached agreement that vitamin $\mathbf{K}$ is also involved in the processes of oxidative phosphorylation in the mitochondria and that its focus of function is at approximately the same position as that of vitamin E.

\section{Paramitochondrial Organelles}

Both by electron microscopy and the separation techniques of differential centrifugation, families of particles within the volume and density range of the mitochondria have been categorized. The Belgian group under deDuve have pioneered this exploration and provided a nomenclature and characterization which in part is dependent on enzymatic criteria. The studies of Chantrenne (1950), of Laird (1954), and subsequently of Novikoff (1956a) have sharpened the delimitations between these units and the conventional mitochondria. In all instances the newly discovered particles have been distinguished by different ribonucleic acid content, an array of specific enzymes either absent from or of slight importance in the mitoshondria, and finally by a lack of inner lamellar structure usual in the mitochondria (Novikoff, 1956b). The particles are especially rich in $\beta$-glucuronidase, cathepsin, acid phosphatase, ribonuclease, and desoxyribonuclease. It was considered, because of the hydrolytic nature of these enzymes, that they were contained in a distinct class of granule which has been provisionally named the "lysosome." It seems that just as the mitochondria occupy a pivotal position in the oxidative and phosphorylative metabolism of the cells, these lighter granules may similarly be storehouses of lytic enzymes. It is obvious at once that disturbance of such particles can unleash a most destructive series of enzymes and that the consequences are certainly pathological. Confirmation of this is afforded by the observations that acid phosphatase, $\beta$-glucuronidase, and cathepsin levels are considerably accentuated in fatty livers induced experimentally. Uricase concentration is shifted to finer particles by the administration of carbon tetrachloride. It may be inferred from such investigations that the damage incurred during the process of cloudy swelling and more advanced cytonecrotic lesions involves not only a direst interference with endergonic processes but activates mechanisms which directly destroy important cellular constituents.

Another interesting particle with special pathological interest has been identified in association with normal and deviated iron metabolism. Electron microscopy has revealed a characteristic structure for the ferritin molecule (Kuff and Dalton, 1957) and confirmed Farrant's (1954) demonstration of the micellar pattern of the molecule. Under normal conditions such particles are distributed uniformly throughout the cytoplasm, with a slight tendency to group more densely between adjacent mitochondria. With the infusion of large amounts of saccharated iron and haemoglobin the cytoplasmic concentrations were vastly augmented. Under such conditions the ferratin micelles appear in otherwise structureless particles of approximately mitochondrial dimension, at which time the reactions and chemical properties typical of haemosiderin may be elicited. Rupture of the bodies is believed to dump cohesive clumps of haemosiderin or catabolized ferratin into the hyaloplasm. The bodies which accumulate the ferratin (Fig. 13) and catalyse its

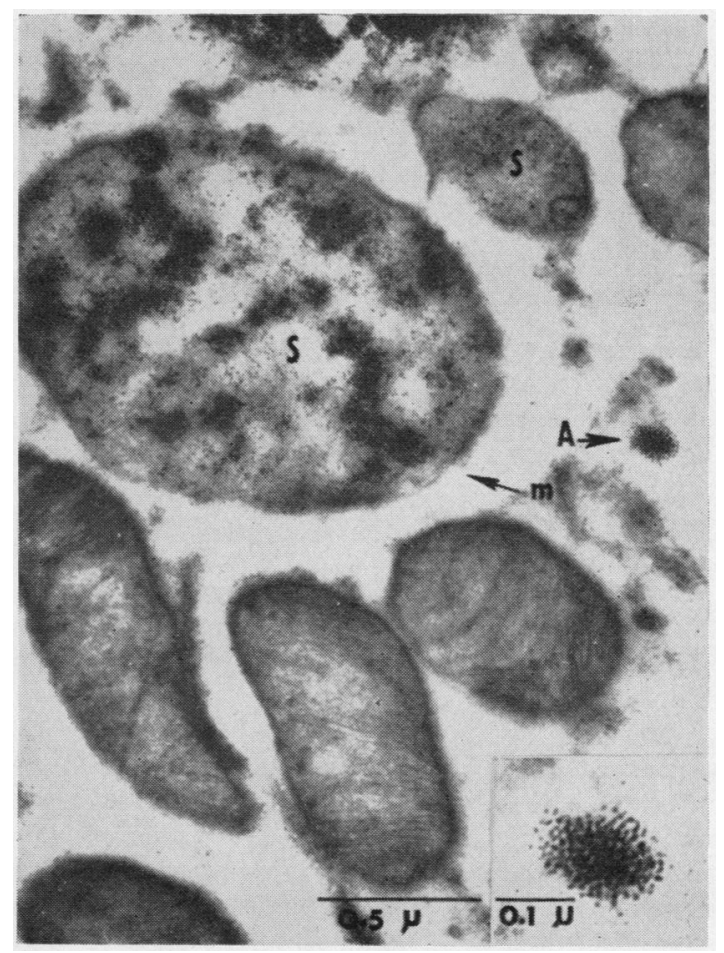

FIG. 13.-This is a photomicrograph of a siderosome as demonstrated by Richter (1957) from liver of an iron-overloaded rat. Some resemblance to the lysosome is apparent. His lower inset shows free ferratin granules indicated at $\mathrm{A}$. 
transformation into haemosiderin are termed "siderosomes" to distinguish them from both mitochondria and lysosomes. At a much earlier date others proposed that the haemosiderin particles were developed within mitochondria during a process of " cytosiderosis" which occurs either in a state of iron overloading or certain nutritional deficiencies. The introduction of electron microscopy, with its revaluation of the fine structure of organelles and of the iron particles, eliminates the mitochondria for the present and substitutes a special functional granule (Richter, 1957).

Numerous other cytoplasmic particles of a special nature have been known for many years, such as those in eosinophil and basophil cells, pituitary chromophil cells, and neutrophil leucocytes. Electron microscopy has revealed that some of these have a peculiar structure, but presents no advance in specifying function. The mast cell granules, however, have been correlated with the release from the cell under the impact of salmine and protamine, as well as of toluidine blue, of histamine together with the dissociation of the specific granules. Electron microscopy has satisfactorily defined this relationship which may be an important part of the inflammatory reaction.

\section{Tissue Defence}

It may be presumed from the fragility of the mitochondria and their vulnerability to noxious agents that they mainly represent disease targets. It is fascinating to discover in one type of cell, and perhaps in others if investigation were pressed home, that they can put the tissue into the attack. Fishman and Silverman (1957) analysed the digestive phase of phagocytosis. Suspensions of polymorphonuclear leucocytes were disintegrated by conventional Potter-Elvehjem homogenization and the homogenate partitioned into fractions, including the mitochondria, although no mention is made of chromophilic granules. The various particles are then dispersed by sonic vibrations and the extracts tested for bactericidal activity. The mitochondrial fraction contained the bulk of the activity, with none evident in the soluble hyaloplasm. The mitochondrial extract was five times more concentrated than the extract from the total cell mass. Characterization demonstrated the lipoprotein nature of the active component, which may be derived from the inner lipoprotein lamellae of the particles. A correlation was indicated between the effectiveness of the bactericidal agent against various microbial strains and the natural invasiveness in the species studied (Fishman, Cole, and Silverman, 1957).

\section{Cytochondria and Carcinogenesis}

The subcellular metabolic and structural patterns of neoplastic cell populations have been defined by several schools concerned especially with the cytoplasmic particulates. It is the pattern of cellular organization rather than absolute quantitation which has received focal interest. Laird (1954) has determined the protein and ribonucleic acid distribution in the particulates and soluble fractions of numerous tumours and $\vec{\circ}$ normal cells and describes distinctive patterns for the neoplasms. It was also well established that $\stackrel{\omega}{\sigma}$ the mitochondrial population of preneoplastic and neoplastic tissues is decreased, due to diminution in number, occasionally in size, and often in $\vec{\sigma}$ structural density of the units (Allard, de Lamirande, and Cantero, 1953). In chemically of induced hepatoma the count per cell may be 을 halved, and there is a greater decrease in many individual oxidative enzymes per gram of mito- $z$ chondrial protein than might be expected from the simple population change. This is compatible with the observation that the oxidative phosphorylation of hepatoma is marginal and also excessively fragile under stress (Emmelot and Bog 1955). Mitochondria isolated from tumours lose their phosphorylating capacity very rapidly coms. pared with control tissues, although supplementing. with diphosphopyridine nucleotide provides almost complete restitution. Wenner and Weinhouse (1953) had previously estimated the diphospho- $\mathbb{Q}$ pyridine nucleotide content of hepatoma mito- $\overrightarrow{\vec{B}}$ chondria and emphasized the paucity and loose binding of the co-enzyme in the neoplastic particles. Carruthers and Suntzeff (1954) attributed this scanty co-enzyme reserve to an excessively active nucleotidase in the tumour mitochondria. In either instance it is also likely from our understanding of normal mitochondrial stability that the ATP-ADP pool and its maintenance participate in the conservation of coenzyme and that this phosphorylating system is primarily defective.

It is unlikely that the mitochondrial behaviour as such is involved directly in the causation of $N$ cancer. Recent information concerning mitochondrial formation de novo in actively dividing 0 cells may afford insight into the deviations of $\omega$ mitochondrial pattern in tumour cells, which are also characterized by nuclear abnormalities. Hoffman and Grigg (1958) have advanced compelling evidence that the mitochondria are? formed from the nuclear membranes during the mitotic cycles in several normal cell types. Earlier work by Hartmann (1948) illustrated the occur- 
rence during chromatolysis of an increase in the mitochondrial population of nerve cells, which Causey and Hoffman (1955) subsequently associated with the specific nuclear alteration and mitochondrial attachments, by electron microscopy. Although this hypothesis is not exclusive and permits alternative variants of mitochondriogenesis, such as fission and derivation from regeneration microbodies after initial fragmentation according to Gansler and Rouiller (1956), they propose it as the chief mode of mitochondriogenesis. Rouiller and Bernhard (1956) observed a great increase of dense microbodies in hepatoma cells, in which they are concentrated adjacent to nuclear and cell membranes.

The defect in mitochondrial reproduction and structure may sequentially influence the ergastoplasm with its gamut of chromidial points and ribonucleic-acid-rich particles. Arcos and Arcos (1958) have advanced information concerning the modification of the macromolecular organization of the microsomes when inducing chemical carcinogenesis. Although they prefer to regard the alterations in the ergastoplasm (microsomal pellets) as the major participant in carcinogenesis, the observations by. Bernhard and Rouiller (1956) that mitochondria govern ergastoplasmic formation, and the finding of Clerici and Cudkowicz (1956) and Emmelot and Bos (1955) that the mitochondria are specifically altered during carcinogenesis, prevent full acceptance of their thesis that the microsomes are more directly involved in carcinogenesis than other cell particles. Observations by Waravdekar, Powers, and Leiter (1956) on sarcoma 37 illustrated a gross increase in drug sensitivity of oxidases contained in the mitochondria. From the various studies of particulates from neoplastic cells it is clear, however, that they all share the disturbed functional and structural abnormality of the cell, especially at the level of intermediate metabolism.

\section{Microsomes}

The microsomes are situated in the endoplasmic reticulum as the units of an intertwining cytoplasmic network. Although a tendency to ramification of the strands is apparent in some cells the extension through the cytoplasm is random. Functionally, the constituents of this chain-like system of vesicles are concerned with many of the cell's synthetic mechanisms, deriving energy from the mitochondria and the substrate from compounds activated by enzyme systems in the hyaloplasm. They are especially rich in ribonucleic acid, which is a recognizable feature in their identification. Thus far the few diseases which are specific to them arise from deficiencies in their enzyme systems.

The microsomes are implicated in two major parameters of cytoplasmic activity. They participate in pathways of protein and steroid synthesis and secondly are responsible for a broad spectrum of reactions concerning detoxication and with conjugation mechanisms. In the first category of synthesis the particles, or the ramifying vesicular system of the endoplasmic reticulum, have a direct controlling influence on protein synthesis, independent of the remote, genetic regulation by the nucleus. Numerous experiments with enucleated cells have verified this. It is the ribonucleic acid moiety of the microsomes which influences protein synthesis in a specific manner so that specific ribonucleic acids induce elaboration of particular proteins and enzymes (Minagawa, 1955). After the amino-acid residues are activated in the presence of soluble ribonucleic acid (Hoagland, 1955) with formation of aminoacyl adenylates they remain firmly attached to the activating enzyme until the residue is incorporated rapidly into the ribonucleic acid of the microsome, which is known to incorporate the aminoresidues more vigorously than all other cell fractions as discerned in Graph No. 2 of Siekevitz's (1952) analysis. This step is a most critically orientating movement which precluded random reaction between the highly reactive anhydrous aminoacyl adenylates with formation of well-defined but heterogeneous proteins (Chantrenne, 1950). It is believed that guanosine phosphate mediates the critical step of incorporation into the microsomal ribonucleoprotein (Hoagland, Zamecnik, and Stephenson, 1957). Thereafter the attached amino-acids are folded into the correct configuration according to one of several possible template mechanisms with the formation of a genetically pre-established configuration (Da'gliesh, 1957). It is most obvious that this is a fertile area for pathological deviation.

The acute interference with the synthetic mechanism, whether by deprivation of an essential amino residue or intervention with an analogue during activation, allows formation of a defective protein, or precludes elaboration of normal protein. On the other hand, under the impetus of more general stress the ribonuclease may be liberated from the nucleus and by participating in the depolymerization of ribonucleic acid impede the incorporation of activated moieties by the particles and cause a general impairment of protein synthesis. This is manifest after toxic 
ionic irradiation when both nuclear ribonuclease is released and mitochondrial structure damaged (Okada and Peachey, 1957). It might be recalled that the phenomenon of cloudy swelling is accompanied by a depletion of the basophilic (ribonucleic acid) constituents of the cell (Drochmans, 1947). In a more chronic form the microsomal synthesis may be impressed into abnormal patterns either by genetic abnormalities in the template construction or the inclusion of metabolic analogues to supplant the normal residues. Some attempt has been made to exploit this hypothesis in tumour chemotherapy. The analogue 3-thiophenealanine causes regression of rat sarcoma transplants and inhibition of antibody formation, with reversal of the effects by phenylalanine (Wissler, Frazier, Soules, Barker, and Bristow, 1956). Similar antimetabolites, including beta-2-thienylalanine, interfere with protein and nucleic acid metabolism and furnish evidence for the likelihood of this occurring in teratogenesis and congenital abnormality (Ham and Eakin, 1957). Studies on urchin eggs' development have been most rewarding with their revelation of intervention of amino-acid antimetabolites in radialization of the organism (Gustafson and Hörstadius, 1955). In the same sphere it has been suggested that differential supplies of simple metabolites may profoundly affect the protein synthesis, as each phase of development has specific quantitative requirements. It is salient that not only protein synthesis is subject to derangement, but that the functioning enzymes which they comprise in most instances are also disorientated, so that the pathological effects are accumulative. Holtfreter (1955) has presented provocative observations on the pathogenic properties of "inductive" agents derived from dead tissue, with exhibition of micro- to acephalic hypomorphoses. Random cell death during morphogenesis may be, at critical stages, as injurious as destruction of select cell groups.

The participation of the microsomes in protein synthesis is a general phenomenon in all cells. Its importance in pathogenesis is well illustrated in two special instances. The first concerns formation of haemoproteins in erythrocyte precursors on the one hand and in parenchymal cells of several tissues on the other. It was demonstrated that particulated fractions from reticulocytes and other earlier red forms, with a high ribonucleic acid content, rapidly incorporate activated amino residues under added stimulus with folic acid and vitamin $B_{12}$, first into the microsomes and subsequently into the globin (Rabinovitz and Olson, 1956). This is illustrated in Fig. 14 which corre-

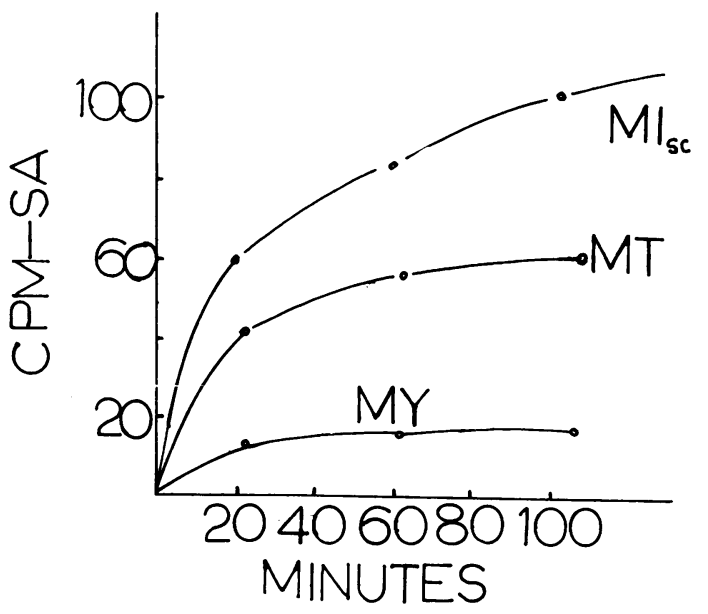

FIG. 14.-This exemplifies the type of activity observed with microsomes from liver, reticulocytes, and parenchymal cells of all types. The preparation utilized consists of particles from skeletal muscle representing micro-sarcosomes $\left(\mathbf{M i}_{\mathbf{s c}}\right)$, mitochondria (MT) and myofibrils (MY). In this tissue mitochondria manifest more than usual activity. Uptake of labelled loucine was measured. Mitochondrial uptake is considerable.

sponds with observations now conventional foro liver muscle and red cell microsome activity. Arn stein has directed attention to the effectiveness of vitamin $B_{12}$ in abetting the protein synthesis of many cell types as well as the erythropoietic series, although the deficiency of this factor is especially salient in erythropoiesis because it simultaneously affects metabolic reactions involved in haem and porphyrin synthesis. Rabinovitz and Olson (1958) also establish the intervention of microsomes in the incorporation of iron into haemoglobin. The synthesis of haem compounds also requires the active intervention of mitochondria in parenchymal cells as manifested in studies of the introduction of iron into the haem by rat liver particulates. It is inferred from this that the timing of haem and protein synthesis in cellular maturation may be sequential and under the influence of cell particulates. In support of this it is known that in erythropoiesis the mitochondria concerned in synthesizing the cell mass and haem disappear somewhat early, whereas the ribonucleic-acid-rich microsomes which direct globin formation and iron inclusion are seen as late as the reticulocyte stage. It is apparent that closer analysis of pathogenesis in deficiency and degenerative anaemias now requires study of the particulates in red cell precursors.

The second special instance in which the microsomes are associated with deviated protein synthesis occurs in the binding of carcinogenic azo 
dyes by the liver cell proteins. Miller and Miller (1947) have concluded on the basis of important considerations that this binding process may be engaged in tumour induction. The preneoplastic maxima of dye binding were closely correlated with specific cytoplasmic hyaline inclusions characteristic of the azo dye intoxication (Price, Harman, Miller, and Miller, 1952). It has subsequently been shown by Hultin (1956) that in early stages of azo dye fixation during maximal hyaline plaque formation the dye is predominantly part of the microsomal protein complex. It is subsequently transferred to soluble or extramicrosomal pools which precipitate in the cytoplasm to form the characteristic plaques. Such protein development may constitute an important aberration in microsomal metabolism and structure as indicated by Arcos and Arcos (1958), who followed the levels of bound dyes in the microsomes and correlated them with altered microsomal structures. In later work Hultin (1957) also detects two species of microsomes manifesting differential binding, and incorporation capacities may in part explain some of the results obtained by these workers. But it is apparent that the carcinogenic activity of the dyes is mediated in some manner through the metabolic processes of the microsomes concerned in protein synthesis.

It so happens also that the microsomes are the site of cholesterol and general sterol synthesis. The mitochondria may contribute high energy for activation, but definitive enzymes are situated in the microsomes. After activation with co-enzyme A and ATP the moiety is incorporated into the microsomes. The initial component may be lanosterol, with further conversion to cholesterol, which requires a TPNH reaction dependent on supernatant enzymes. Perhaps one of the most significant observations in this field is that the application of ribonuclease blocks the utilization of mevalonic acid in the synthesis of cholesterol (Wright, Cleland, Dutta, and Norton, 1957). This brings the synthetic pathways of proteins and the sterols into close conjunction, and may well be scrutinized for aspects of lipoprotein aberration, since this is the proper site for the appraisal of the basic defect in lipid storage diseases.

In its second parameter of activity the microsomal system has the capacity to oxidize and conjugate a wide variety of drugs and extraneous compounds. Both mechanisms have been classified as detoxicating processes, and a list of the types of reactions involved in oxidative detoxications is presented in Table III. Non-specificity is a characteristic of these enzyme mechanisms, which

\section{TABLE III}

Hydroxylation of aromatic rings

$$
\mathrm{CH}_{3}-\mathrm{CO}-\mathrm{NH}-\mathrm{C}_{6} \mathrm{H}_{5}-\mathrm{CH}_{3}-\mathrm{CO}-\mathrm{N}-\mathrm{C}_{6} \mathrm{H}_{4}-\mathrm{OH}
$$

Oxidation of side chains

$$
\mathrm{R}-\mathrm{CH}_{2} \mathrm{CH}_{2} \mathrm{CH}_{2}-\mathrm{CH}_{3} \longrightarrow \rightarrow \mathrm{R}-\mathrm{CH}_{2} \mathrm{CH}_{2}-\mathrm{CH}_{2} \mathrm{OH}-\mathrm{CH}_{3}
$$

N-Dealkylation

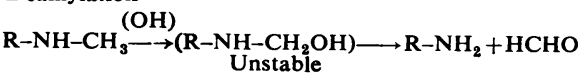

$$
\begin{aligned}
& \mathrm{R}-\mathrm{O}-\mathrm{CH}_{3} \stackrel{(\mathrm{OH})}{\rightarrow}\left(\underset{\mathrm{R}}{-\mathrm{O}-\mathrm{CH}_{2}-\mathrm{OH}}\right)-\mathrm{R}-\mathrm{OH}+\mathrm{HCHO}
\end{aligned}
$$

Deamination

$$
\begin{aligned}
& \left.\mathrm{R}-\mathrm{CH}_{2}-\mathrm{CH}\left(\left(\mathrm{NH}_{2}\right)\right)-\mathrm{CH}_{3} \longrightarrow(\mathrm{OH})\left(\mathrm{CH}_{2}-\mathrm{COH}\left(\left(-\mathrm{NH}_{2}\right)\right)-\mathrm{CH}\right)_{3}\right) \\
& \text { Sulphoxide formation } \quad \longrightarrow \mathrm{R}-\mathrm{CH}_{2}-\mathrm{CO}-\mathrm{CH}_{3}+\mathrm{NH}_{3} \\
& \text { R-S- } \mathrm{CH}_{3} \longrightarrow(\mathrm{OH}) \underset{\text { Unstable }}{\longrightarrow} \rightarrow(\mathrm{CH}-\mathrm{OH}) \longrightarrow \mathrm{R}-\mathrm{SO}-\mathrm{CH}_{3}
\end{aligned}
$$

are not critically engaged in normal sequential metabolism, so that deviation to handling foreign compounds does not deplete the organism of essential enzymes. They have a further special characteristic feature of acting mainly on lipidsoluble non-polar compounds. In mammals this is of considerable importance in order to prevent accumulation of toxic lipid-soluble compounds which might tend to concentrate in dangerous quantity. Metabolism of compounds with high oil-to-water partition is probably associated with the lipid cortex of the microsome which can be penetrated only by suitable non-polar molecules. This is an important arena for the experimental pathologist in so far as the competence of these systems is dependent on an adequate range of enzymes. Sex and species differences have been discerned and microsomal variation may be the explanations for such metabolic difference in handling compounds. It is conjectural that certain instances of drug hypersensitivity pertain to the efficiency of this system.

One of the most fascinating recently observed diseases is due to a defect in this system which is responsible for constitutional non-haemolytic hyperbilirubinaemia (Gilbert's disease). It is ascribed to a failure by the liver microsomes to conjugate bilirubin with glucuronide, which is the soluble direct form and susceptible to excretion. Failure in conjugation prevents adequate excretion and establishes a hyperbilirubinaemic state. With the use of a special mutant strain of Wistar rat, afflicted with this syndrome, it was found that the microsomal fraction lacks a glucuronyl transferase, which shifts the glucuronide from uridinediphosphate-glucuronic acid to the bilirubin 
molecule (Schmid, Axelrod, Hammaker, and Swarm, 1958). It is a general defect in glucuronyl transfer as shown with the use of o-aminophenol as acceptor. Later work has extended the existence of such a deficiency to foetal and newborn livers, where it assumes considerable significance in relation to the mechanism of icterus which is so frequent at that age. Any abnormal tendency to haemolysis will be an overload for foetal and newborn livers, and remarkably dangerous in view of the suspectibility of the foetal neurons to bilirubin encephalopathy (Zetterström and Ernster, 1956). It is likely that variable degrees of this and kindred so-called "detoxicating" mechanisms may account for types of cytoplasmic sensitivities to extraneous compounds at subliminal concentrations.

\section{Summary}

In the hundred years since the publication of Virchow's classic synthesis on cell pathology the orientation provided by that definitive work has been sufficient. It has also indicated the logical further step into the field of cytoplasmic nutrition and function which govern the basic cellular reactivity in health and disease. The concept of the cell as a nutritional unit suggested the manner in which the cell suffered damage while reacting to diverse forms of injury or malnutrition, but realization of the mechanisms engineering this damage within the cell was denied owing to the inadequacy of extant knowledge concerning cytoplasmic structure and function then current. Within the last decade the panorama of subcellular structure and function has opened up before us, thrusting upon the pathologist the novel task of pressing beyond the cellular into the subcellular range of disease. In this advance of cellular pathology to a new level the acceptance of the particulate structure of cytoplasm has allowed recognition of subcellular differentiations which serves to localize the finer sites of disease processes.

\section{REFERENCES}

Abei, H., and Abelin, I. (1953). Biochem. Z., 324, 364.

Aisenberg, A. C., and Potter, V. R. (1957). J.biol. Chem., 224, 1115. Ajl, S. J., Rust, J. Jr., Woebke, J., and Hunter, D. H. (1956). Fed. Proc., 15, 581.

Allard, C., De Lamirande, G., and Cantero, A. (1953). Canad. J. med. Sci., 31, 103.

- Mathieu, R., De Lamirande, G., and Cantero, A. (1952). Cancer Res., 12, 407.

Altmann, R. (1894). Die Elementarorganismen und ihre Beziehungen $z u$ den .Zellen, 2nd ed. Veit, Leipzig.

Anitschow, N., and Aschoff, L. (1914). Verh. dtsch.path. Ges., 17, 103. Anitschow, N., an Ascos, M. (1958). Biochim. Biophys. Acta, 28, 9. Ball, E. G., and Barrnett, R. J. (1957). J. biophys. biochem. Cytol., 3, 1023 .

Bartley, W., and Amoore, J. E. (1958). Biochem. J., 69, 348.

Bensley, R. R., and Hoerr, N. L. (1934). $\begin{aligned} & \text { Anat. Rec., 60, } 449 . \\ & \text { Antley, }\end{aligned}$
Bernhard, W., and Rouiller, C. (1956). J. biophys. biochem. Cytol., 2 (Suppl.), p. 73.

Bernheimer, A. W., Lazarides, P. D., and Wilson, A. T. (1957). J. exp. Med., 106, 27.

Birbeck, M. S. C., and Reid, E. (1956). J. biophys. biochem. Cytol. 2, 609.

Bouman, J., and Slater, E. C. (1957). Biochim. Biophys. Acta, 26, 624 Carlson, A. S., Kellner, A., and Bernheimer, A. W. (1956). J. exp. Med., 104, 577.

- and Freeman, E. B. (1957). Ibid., 106, 15.

Carruthers, C., and Suntzeff, V. (1954). Cancer Res., 14, 29.

Causey, G., and Hoffman, H. (1955). Brit. J. Cancer, 9, 666.

Chantrenne, H. (1950). Biochim. Biophys. Acta, 4, 484.

Christie, G.S., and Judah, J. D. (1953). Proc. roy. Soc. B., 141, 420.

Clarke, N. (1958). Thesis, M.D. University College, Dublin.

Claude, A. (1946). J. exp. Med., 84, 51, 61 .

Cleland, K. W., and Slater, E. C. (1953). Quart. J. micr. Sci., 94, 329.

Clerici, E., and Cudkowicz, G. (1956). J. nat. Cancer Inst., 16, 1459.

Cooper, C., and Lehninger, A. L. (1956). J. biol. Chem., 219, 489.

Cooper, C., and Lehninger, A. L. (1956).
Crane, F. L. (1958). Soil Sci., 85, 78.

- Hatefi, Y., Lester, R. L., and Widmer, C. (1957). Biochim. Biophys. Acta, 25, 220.

Dalgliesh, C. E. (1957). Science, 125, 271.

Dalton, A. J. (1953). Int. Rev. Cytol., 2, 403.

Devlin, T. M., and Lehninger, A. L. (1956). J. biol. Chem., $219,507$.

Dianzani, M. U. (1954). Biochim. Biophys. Acta, 14, 514.

(1955). Ibid., 17, 391.

(1957). Biochem. J., 65, 116.

and Viti, I. (1955). Ibid., 59, 141.

Dounce, A. L., Witter, R. F., Monty, K. J., Pate, S., and Cottone, M. A. (1955). J. biophys. biochem. Cytol, $1,139$.

Drochmans, P. (1947). Experientia (Basel), 3, 421 .

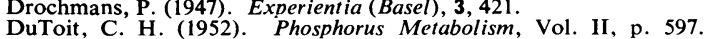
Edited by McElroy, W. D., and Glass, Bentley. The Johns Hopkins Press, Baltimore.

Duve, C. de, and Berthet, J. (1954). Int. Rev. Cytol., 3, 225.

- Pressman, B.C., Gianetto, R., Wattiaux, R., and Appelmans, F. (1955). Biochem. J., 60, 604.

Emmelot, P. and Bos, C. J. (1955). Biochim. Biophys. Acta, 16, 620.

Ernster, L. (1956). The Enzymic Organization of Mitochondria and Its Role in the Regulation of Metabolic Activities in Animal Tissues. Almquist and Wiksells, Uppsala.

Herlin, L., and Zetterström, R. (1957). Pediatrics, 20, 647.

and Löw, H. (1955). Exp. Cell Res., Suppl. 3, 133 .

- and Navazio F. (1957). Biochim. Biophys. Acta, 26, 408.

Farrant, J. L. (1954). Ibid., 13, 569.

Faurá-Fremiet, E. (1910). Arch. Anat. micr. Morph. exp., 11, 457. Festenstein, G. N., Heaton, F. W., Lowe, J. S., and Morton, R. A. (1955). Biochem. J., 59, 558.

Fishman, M., Cole, L. J., and Silverman, M. S. (1957). J. exp. Med., 105, 529.

_ and Silverman, M. S. (1957). Ibid., 105, 521.

Fonnesu, A., and Severi, C. (1956), J.biophys.biochem. Cytol., 2, 293.

Frederic, J. (1958). Arch. Biol. (Liège), 69, 167.

Frey-Wyssling, A. (1948). Submicroscopic Morphology of Protoplasm and Its Derivatives. Elsevier Publishing Co., New York and Amsterdam.

Gallagher, C. H., Gupta, D. N., Judah, J. D., and Rees, K. R. (1956). J. Path. Bact. 72, 193.

Gamble, J. L. (1957). J. biol. Chem., 228, 955.

Gansler, H., and Rouiller, C. (1956). Schweiz. Z. allg. Path., 19, 217

Grabe, B. (1958). Proc. 4th International Congress Biochemistry, Vienna, p. 60.

Green, D. E.., Loomis, W. F., and Auerbach, V. H. (1948). J. biol. Chem., 172, 389.

Gustafson, T., and Horstädius, S. (1955). Exp. Cell Res., Suppl. $3,170$.

Ham, R. G., and Eakin, R. E. (1957). Fed. Proc., 16, 191.

Harman, J. W. (1950a). Exp. Cell Res., 1, 382.

(1950b). Ibid., 1, 394.

(1954). Fed. Proc., 13, 430.

(1955). Amer. J. phys. Med., 34, 68

(1956). Int. Rev. Cytol., 5, 88

(1958). In preparation.

and Feigelson, M. (1952). Exp. Cell Res., 3, 509.

and Feigelson, M. (1952). Exp. Cell Res.

and Kitiyakara, A. (1955). Ibid., 8, 411.
Hartmann, J. F. (1948). Anat. Rec., 100, 49

Hatefi, Y., and Lester, R. L. (1958). Biochim. Biophys. Acta, 27, 83.

Hate Lester, R. L., and Ramasarma, T. (1958). Fed. Proc., 17, 238.

Hift, H., and Strawitz, J. G. (1958). Proc. Soc. exp. Biol.' (N.Y.), 98 235 .

Hoagland, M. B. (1955). Biochim. Biophys. Acta, 16, 288.

Hoagland, M. B. (19. and Stephenson, M. L. (1957). Ibid., 24, 215.

Hoffman, H., and Grigg, G. W. (1958). Exp. Cell Res., 15, 118.

Hogeboom, G. H. Claude, A., and Hotchkiss, R. D. (1946). J. biol. Chem., 165, 615.

Holtfreter, J. (1955). Exp. Cell Res., Suppl. 3, 188.

Huennekens, F. M., and Green, D. E. (1950). Arch. Biochem., 27, 418. Hultin. T. (1956). Exp. Cell Res., 10, 697.

(1957). Ibid., 12, 290. 
Hunter, F. E., Davis, J., and Carlat, L. (1956). Biochim. Biophys. Acta, 20, 237.

- and Ford, L. (1955). J. biol. Chem., 216, 357.

Judah, J. D., and Williams-Ashman, H. G. (1951). Biochem. J., 43, 33.

Kaltenbach, J. C., and Harman, J. W. (1955). Exp. Cell Res., 8, 435.

Kaltenbach, J. P. (1954). Ibid., 7, 568.

Kellner, A., Bernheimer, A. W., Carlson, A. S., and Freeman, E. B. (1956), J. exp. Med., 104, 361 .

Kielley, W. W., and Bronk, J. R. (1958). J. biol. Chem., $230,521$.

Kitiyakara, A., and Harman, J. W. (1953). J. exp. Med., 97, 553.

Kölliker, A. (1856). Z. wiss. Zool., 8, 311

Kuff, E. L., and Dalton, A. J. (1957). J. Ultrastructure Res., 1, 62. Hogeboom, G. H., and Dalton, A. J. (1956). J.' biophys. biochem. Cytol., $2,33$.

Laird, A. K. (1954). Exp. Cell Res., 6, 30.

Lehninger, A. L., and Ray, B. L. (1957). Biochim. Biophys. Acta, 26, 643 .

Levin, E., Johnson, R. M., and Albert, S. (1957). J. biol. Chem., 228, 15.

Liébecq, C., and Peters, R. A. (1949). Biochim. Biophys. Acta, 3, 215.

Maley, G. F., and Lardy, H. A. (1953). J. biol. Chem., 204, 435.

Martius, C. (1956). Proc. 3rd International Congress Biochemistry, Brussels, 1955, pp. 1-9.

Miller, E. C, and Miller, J. A. (1947), Cancer Res. 7, 468.

Minagawa, T. (1955). Biochim. Biophys. Acta, 16, 539.

Monné, L. (1948). Advanc. Enzymol., 8, 1.

Montgomery, C. M., and Wobb, J. L. (1956). J. biol. Chem., $221,359$.

Nason, A., Donaldson, K. O., and Lehman, I. R. (1957). Trans. New York Acad. Sci., Ser. 2, $20,27$.

Nilsson, O. (1958). J. Ultrastructure Res., 1, 375.

Novikoff, A. B. (1956a). Science, 124, 969

Nov (1956b). J. biophys. biochem. Cytol., 2 (Suppl.), p. 65 - Beaufay, H., and Duve, C. de (1956). Ibid., 2 (Suppl.), p. 179.

Nygaard, A. P. (1953). J. biol. Chem., 204, 655 .

Dianzani, M. U., and Bahr, G. F. (1954). Exp. Cell Res., 6, 453 .

Oberling, C., Bernhard, W., Febvre, H. L., and Harel, J. (1951). Rev. Hémat., 6, 395.

Okada, S., and Peachey, L. D. (1957). J. biophys. biochem. Cytol., $3,239$.

Opie, E. L. (1948). J. exp. Med., 87, 425.

Palade, G. E. (1952). Anat. Rec., 114, 427.

- (1955a). J. biophys. biochem. Cytol., 1, 59. (1955b). Ibid., 1, 569.

and Siekevitz, P. (1956). Ibid., 2, 671.

Panagos, S., Beyer, R. E., and Masoro, E. J. (1958). Biochim. Biophys. Acta, 29, 204.

Pappenhei ner, A. M., and Hendee, E. D. (1947). J. biol. Chem., 171, 701 .

- and Williams, C. M. (1952). J. gen. Physiol., 35, 727.

Powers, E. L., Ehret, C. F., and Roth, L. E. (1955). Biol. Bull., 108, 182.
Price, J. M., Harman, J. W., Miller, E. C., and Miller, J. A. (1952). Cancer Res., 12, 192.

Purkinje, J. E. (1825). Symbolae ad ovi avium historium ante incubationem. Lipsiae.

Raaflaub, J. (1953). Helv. Physiol. Acta, 11, 157.

Rabinovitz, M., and Olson, M. E. (1956). Exp. Cell Res., 10, 747.

(1958). Nature (Lond.), 181, 1665.

Recknagel, R. O., and Malamed, S. (1958). J. biol. Chem., 232, 705.

Rhodin, J. (1954). Correlation of Ultrastructural Organization and Function in Normal and Experimentally Changed Proximal Convoluted Tubule Cells of the Mouse Kidney. Stockholm.

Richter, G. W. (1957). J. exp. Med., 106, 203.

Rouiller, C., and Bernhard, W. (1956). J. biophys. biochem. Cytol., 2 (Suppl.), p. 355.

Schmid, R., Axelrod, J., Hammaker, L., and Swarm, R. L. (1958). J. clin. Invest., $37,1123$.

Schneider, W. C., and Hogeboom, G. H. (1951). Cancer Res., 11, 1.

Seifriz, W. (1942). Symposium on the Structure of Protoplasm. Iowa State College Pross, Ames.

Severi, C., and Fonnesu, A. (1956). Proc. Soc. exp. Biol. (N.Y.), 91,368 .

Siekevitz, P. (1952). J. biol. Chem., 195, 549.

Sjöstrand, F. S. (1956). Int. Rev. Cytol., 5, 455.

- and Baker, R. F. (1958). J. Ultrastructure Res., 1, 239.

Slater, E. C. (1958). Proc. 4th International Congress Biochemistry, Vienna, Symposium XI, Preprint 11.

- and Cleland, K.W. (1953). Biochem. J., 55, 566.

Strawitz, J. G., and Hift, H. (1956). Proc. Soc. exp. Biol. (N.Y.), 91,641 .

Tapley, D. F. (1955). Bull. Johns Hopk. Hosp. 96, 274.

Theirs and Cooper, C. (1956). J. biol. Chem., 222, 341. International Congress Biochemistry, Vienna. Int. Abstr. biol. $S c i$. ., Suppl., 1958 , p. 73.

Tyler, D. B. (1951). Amer. J. Physiol., 164, 467.

Vester, J. W., and Stadie, W. C. (1957). J. biol. Chem., 227, 669.

Waksman, B. H., Adams, R. D., and Mansmann, H. C., Jr. (1957). J. exp. Med., 105, 591 .

Waravdekar, V. S., Powers, O., and Leiter, J. (1956). J. nat. Cancer Inst., 16, 1443.

Inst., 16, 1443.
Weinreb, S., and Harman, J. W. (1955). J. exp. Med., $101,529$.

Wenner, C. E., and Weinhouse, S. (1953). Cancer Res., 13, 21.

Wissler, R. W., Frazier, L. F., Soules, K. H., Barker, P., and Bristow, E. C. (1956). A.M.A. Arch. Path., 62, 62.

Witter, R. F., and Cottone, M. A. (1956). Biochim. Biophys. Acta, $22,372$.

Wright, L. D., Cleland, M., Dutta, B. N., and Norton, J. S. (1957). J. Amer. chem. Soc., 79, 6572 .

Zetterström, R., and Ernster, L. (1956). Nature (Lond.), 178, 1335.

Ziegler, D. M., Linnane, A. W., and Green, D. E. (1958). Biochim. Biophys. Acta, 28, 524 .

Zollinger, H. U. (1948). Schweiz. Z. Path., 11, 617.

(1950). Rev. Hémat., 5, 696. 